\title{
Die internationale Finanzkrise: Ursachen, Treiber, Veränderungsbedarf und Reformansätze
}

\author{
von \\ Prof. Dr. Bernd Rudolph, München*
}

Inhaltsübersicht

ZGR 2010, 1-47

I. Problemstellung $\ldots \ldots \ldots \ldots \ldots \ldots \ldots \ldots \ldots \ldots \ldots \ldots \ldots \ldots \ldots \ldots \ldots \ldots \ldots \ldots, 2$

II. Entstehung und Verlauf der internationalen Finanzkrise ............ 4

1. Die Entwicklung des amerikanischen Marktes für Wohnungsbaudarlehen 4

2. Problematische Trends und Exzesse seit der Jahrhundertwende ........ 6

3. Die Märkte für Mortgage Backed Securities ................. 8

4. Von der Subprime Krise zur internationalen Finanzkrise ........... 17

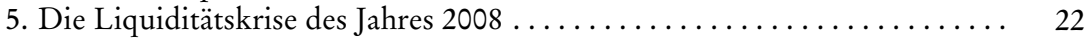

6. Die wichtigsten Treiber der internationalen Finanzkrise ........... 24

III. Lösungs- und Reformvorschläge zur zukünftigen Krisenvermeidung . . . . . 26

1. Analyserahmen der Ansatzpunkte für Veränderungen ............ 26

2. Reformen der Struktur der Bankenaufsicht und des Regulierungsrahmens $\quad 29$

3. Verbesserungen der bankaufsichtlichen Regelwerke ............ 32

4. Abbau von Friktionen im Prozess des Kreditrisikotransfers .......... 39

5. Verbesserungen in der Risikokontrolle und im Risikomanagement ...... 45

IV. Ausblick . . . . . . . . . . . . . . . . . . 46

Die internationale Finanzkrise hat die Dringlichkeit von Veränderungen im Verbalten vieler Finanzintermediäre deutlich gemacht. Risikomanagementsysteme müssen verbessert und um geeignete Stresstest, Sensitivitätsanalysen und Risikokonzentrationsrechnungen ergänzt werden. Die Krise belegt aber auch, dass die Ansätze der Regulierung und Kontrolle des Finanzsystems überdacht und verändert werden müssen, wenn die Bankenaufsicht in $\mathrm{Zu}$ kunft das Eintreten systemischer Risiken verhindern soll. Dazu müssen die Wirkungsmechanismen des Risikomanagements der Banken besser verstanden und aus der Makrosicht der Finanzmärkte beurteilt werden. Die neuen Regeln und Steuerungsmechanismen dürfen nicht an den verfolgten Zielsetzungen vorbeifübren und möglicherweise sogar wieder zyklusverstärkend oder anderweitig kontraproduktiv wirken.

Der Beitrag beschreibt und analysiert die Entwicklung des amerikanischen Marktes zur Finanzierung von Wohnimmobilien seit dem New Deal der 1930er Jabre und gibt einen kritischen Einblick in die Gefabren der Zersplitterung der Wertschöpfungsketten im Finanzdienstleistungsbereich, in die Schwachstellen des modernen Kreditrisikotransfers mit seinen komplexen Produkten sowie in die Defekte der ökonomischen und regulativen Systeme zur Risikomessung und Risikostenerung der Banken. Auf der Basis dieser Analyse

* Institut für Kapitalmarktforschung und Finanzierung, Ludwig-Maximilians-Universität München. Der Verfasser dankt Marcus Lutter, Philipp Gann, Albert Schaber und Julia Scholz für hilfreiche Anmerkungen. Alle Fehler und Mängel der Arbeit gehen zu Lasten des Verfassers. 
werden wichtige Vorschläge zur Verbesserung des Risikomanagements der Kreditinstitute und zur Konzeption einer auf makroprudentielle Ziele ausgerichteten Regulierung diskutiert, die die Systemrisiken der Finanzintermediäre in den Mittelpunkt der Betrachtung stellt.

The international financial crisis has revealed the urgency of changes in the goals, in the actions and in the business models of many financial intermediaries around the world. Risk management systems must be effectively improved and completed with better stress testing models, sensitivity analysis specifications und measures for risk concentration at the banks' institutional level. However, the crisis has also shown that the approaches of regulation and supervision at the level of the entire financial system must be reconsidered and modified with the aim of preventing systemic risks and procyclical developments in the markets. For that purpose the mechanisms and network effects of banks' risk management systems must be better understood and evaluated from a macroprudential perspective. The new rules must not bypass the intended goals of banking regulation.

This article analyses important developments in the US market for home loan finance since the New Deal of the 1930 sand points out the dangers of breaking up the value and risk chain, the weaknesses of modern credit risk transfer with its complex instruments and, from our knowledge today, the defects of the banks' economic and regulative risk management systems. On this basis the article presents and discusses some important proposals for the revision of microprudential and the introduction of macroprudential regulation.

\section{Problemstellung}

Die in der Mitte des Jahres 2007 offen zutage getretene Krise am amerikanischen Markt für verbriefte zweitrangige Hypothekenforderungen (Subprime Krise) und die daraus entstandene internationale Finanzkrise sind von verschiedenen Akteuren und Umfeldbedingungen an den Finanzmärkten verursacht, verstärkt und weltweit verbreitet worden. Zu den Akteuren gehörten nicht nur die Banken mit ihrem Management und ihren Mitarbeitern. Es gehörten auch andere Finanzintermediäre wie die Mortgage Broker, die Ratingagenturen und die Hedgefonds dazu, aber auch jene Institutionen, die die Banken und das Bankensystem kontrollieren sollen, nämlich die Institutionen der Bankenaufsicht und die Zentralbanken. Ein weiterer wichtiger Treiber war der amerikanische Staat, der einerseits auch Bürger ohne ausreichende Ersparnisse und Einkommen durch steuerliche Anreize und vielfältige Absicherungsmöglichkeiten zum Erwerb von Wohneigentum ermutigt bzw. verleitet und andererseits im September 2008 der in Schwierigkeiten geratenen Lehman Bank seine Hilfe verweigert hat. Schließlich gehören zu den Treibern der Krise auch die weltweit nach Anlagemöglichkeiten suchenden institutionellen Investoren, Staatsfonds, Finanzintermediäre und Banken, die die Akteure am amerikanischen Kapitalmarkt gedrängt haben, immer weitere Finanztitel zu kreieren und zu emittieren, um für (vermeintlich) risikoarme, aber ertragreiche Anlagemöglichkeiten in US-Dollar zu sorgen. Die Bewertung des komplexen Ursachenbündels, das die Krise ausgelöst und dann weltweit verbreitet hat, hängt davon ab, ob menschliches Versagen einzelner Beteiligter, 
Schwachstellen im Risikomanagement der Banken oder globale Ungleichgewichte und makroökonomische Fehlentwicklungen oder Strukturprobleme im Finanzsystem als Auslöser oder Verstärker der Krise angesehen werden. Zu unterscheiden ist dementsprechend, ob eher das mikroökonomische Entscheidungsverhalten der Akteure oder makroökonomische Stellgrößen ins Zentrum der Bewertung gerückt werden.

In diesem Beitrag sollen insoweit vorwiegend mikroökonomische Gesichtspunkte in den Blickwinkel genommen werden, als das Verhalten der Finanzintermediäre im bestehenden Regulierungsrahmen der Bankenaufsicht zum Ausgangspunkt von Veränderungs- bzw. Verbesserungsvorschlägen genommen wird. Ob diese Sichtweise des Ursachenkomplexes gegenüber der Perspektive der weltweiten makroökonomischen Ungleichgewichte oder der Untersuchung des individuellen Fehlverhaltens einzelner Bankmanager, Großanleger oder politischer Entscheidungsträger wichtiger oder weniger bedeutsam ist, lässt sich letztlich nicht feststellen. Die mikroökonomische Sichtweise hat aber für die im weiteren Verlauf dieses Beitrags diskutierten Vorschläge insoweit eine besondere Bedeutung, als sich die internationalen Anstrengungen um diese Sichtweise konzentrieren und grundlegende Änderungen beispielsweise im Risikocontrolling der Banken oder in den bankaufsichtlichen Regelwerken nur vorgeschlagen werden sollten, wenn sich die damit intendierten positiven Veränderungen inhaltlich begründen und in ihrer Wirkung abschätzen lassen. So sollten, wenn der geschäftspolitische Spielraum der Banken und anderer finanzieller Institutionen eingeschränkt, neue Informationspflichten eingeführt und die Kontroll- und Prüfungsgremien der Banken neuen Regelungen unterworfen werden, die kritischen Wirkungsmechanismen der Banksteuerung und der Bankenaufsicht identifiziert sein, damit die überarbeiteten oder neuen Regeln und Steuerungsmechanismen nicht an den verfolgten Zielsetzungen vorbeiführen und möglicherweise sogar kontraproduktiv wirken. Die Rettungsbemühungen der verschiedenen Staaten im Zuge der internationalen Finanzkrise haben die Bedeutung der Banken und Finanzmärkte für die Realwirtschaft deutlich gemacht.

Der vorliegende Beitrag beschäftigt sich im nachfolgenden zweiten Abschnitt mit der Aufarbeitung der Hintergründe der auslösenden Subprime-Krise sowie der nachfolgenden internationalen Banken- und Finanzkrisen. Auf dieser Basis werden dann im dritten Abschnitt Vorschläge diskutiert, wie die erkannten Schwachstellen im Finanzsystem repariert oder behoben werden können. Dabei kann keine Vollständigkeit der Vorschläge angestrebt werden und die Vorschläge sollen auch nicht in ihren administrativen Umsetzungen und den damit verbundenen Detailproblemen bewertet werden. Vielmehr wird das Augenmerk insbesondere auf grundlegende Prinzipien gelenkt, wie in Zukunft das Risikomanagement, die interne Banksteuerung und die Bankenaufsicht reformiert und auf die Zielsetzung der Vermeidung von Finanzkrisen besser ausgerichtet werden können. Die speziellen Probleme des Ein- 
greifens der Notenbanken in die Finanzkrise zur Aufrechterhaltung bzw. Erleichterung der Refinanzierung der Kreditinstitute werden im Folgenden ebenso wenig thematisiert wie die Fragen, die sich bei der Etablierung von Rettungspaketen und Bad Banks ergeben, die von den Regierungen weltweit installiert worden sind. Der Fokus liegt vielmehr auf den längerfristig wirkenden einzelwirtschaftlichen und regulativen Maßnahmen, die als Antworten auf die internationale Finanzkrise vorgeschlagen oder bereits politisch umgesetzt worden sind.

\section{Entstehung und Verlauf der internationalen Finanzkrise}

\section{Die Entwicklung des amerikanischen Marktes für Wohnungsbaudarlehen}

Die Entstehung und der Verlauf der internationalen Finanzkrise sind kaum zu erklären, wenn man nicht einen Blick auf die Entwicklung des Marktes für Wohnungsbaudarlehen in den USA wirft, der sich seit der Zeit des New Deal in den 1930er Jahren herausgebildet hat und schließlich zum Ausgangspunkt der Subprime Krise wurde, die dann ihrerseits der Auslöser bzw. Anlass der internationalen Finanzkrise wurde. Der Markt für Wohnungsbaudarlehen sowie der Subprime Markt als qualitativ niedriges Marktsegment der Wohnungsbaufinanzierung in den USA nahmen im Lauf der Jahre eine immer wichtigere Rolle bei der sozialen Absicherung amerikanischer Familien und als Baustein zum „American Dream“ ein. Ein wichtiges Element der Wohnungsbaufinanzierung stellte dabei die Verfügbarkeit erstrangiger Festzinskredite für die Immobiliennachfrager mit niedrigem Einkommen dar, deren Möglichkeiten der Eigenkapitalbildung begrenzt sind und die daher staatlicherseits in verschiedener Weise unterstützt wurden.

Der Markt für Wohnungsbaukredite hat sich mit vielfältigen Spielarten und Veränderungen nach dem Zweiten Weltkrieg weiterentwickelt, wobei als besonders bemerkenswerte Neuerung in den 80er Jahren die Refinanzierung der Darlehen über die Emission von Mortgage Backed Securities (MBS) üblich geworden ist. Darunter versteht man durch einen Pool von Hypothekenforderungen (Mortgages) als Sicherheiten gedeckte (Backed) Wertpapiere (Securities), eine spezifische Variante der Asset Backed Securities (ABS). ${ }^{1}$ Durch diese Form der Finanzierung und des Risikotransfers müssen die Hypothekenforderungen und die damit verbundenen Risiken nicht mehr während der gesamten Laufzeit in den Bilanzen der Kredit gewährenden Banken, der Originatoren verbleiben, sondern werden an die Kapitalmärkte weitergereicht und können damit weltweit auf viele unterschiedliche Risikoträger verteilt werden. In der Form strukturierter Anleihen werden die Risiken

1 Vgl. zu einem Überblick über die neuen Instrumente für den Transfer von Kreditrisiken Rudolph ET AL., Kreditrisikotransfer. Moderne Instrumente und Methoden, 2007. 
insbesondere in die Portfolios institutioneller Anleger wie Pensionskassen und Versicherungen aufgenommen, wandern zum großen Teil aber auch in die Bücher ausländischer Investoren und teilweise auch zu den Banken wieder zurück, nun aber in deren Wertpapierportfolios. Die einsetzende „Wanderungsbewegung“, die über die etablierten Grenzen der Bankmärkte hinausreichte, war statistisch nur in Ansätzen erfasst, so dass auch kaum Vorstellungen über die weltweite Verteilung der Risiken bestanden. Der Markt für Mortgages Backed Securities in den USA hatte seit den 1980er Jahren stetig an Größe und Liquidität gewonnen und bildete sich in den letzten Jahren sogar als größtes Segment des amerikanischen Anleihenmarktes vor dem Markt für staatliche Anleihen und für andere forderungsbesicherte Papiere heraus.

Typisch für das amerikanische System der Wohnungsbaufinanzierung ist nicht nur die kapitalmarktorientierte Refinanzierung über MBS, sondern auch die Garantiestellung durch Government Sponsored Enterprises (Agencies), wozu insbesondere die im September 2008 ganz verstaatlichten Institutionen Fannie Mae und Freddie Mac gehören. Bis zur Jahrhundertwende dominierten die von den Agencies unterstützten Wohnungsbaufinanzierungen, während in den Jahren danach der Marktanteil der Hypothekeninstitute wuchs, die nicht staatlich gefördert wurden (Non Agencies). Dementsprechend verschoben sich auch die Anteile der Mortgage Backed Securities (MBS), die durch Hypotheken mit oder ohne staatliche Garantie gedeckt waren. Die nachfolgende Tabelle macht das Ausmaß des Bestandswachstums der Mortgage Backed Securities sowie der Verschiebung der Anteile zugunsten der Non AgencyMBS deutlich. ${ }^{2}$ Ebenso typisch wie die Tätigkeit der Agencies ist die Versicherung der Ausfallrisiken von Anleihen durch Kreditversicherungsgesellschaften (Monoliner), die auch die Rückzahlung von Anleihen garantieren, die durch nur unzureichend besicherte Kredite unterlegt sind.

Das hier nur kurz skizzierte System der amerikanischen Wohnungsbaufinanzierung trug über viele Jahrzehnte zur Umsetzung der politischen Zielsetzung bei, auch wenig begüterte amerikanische Bürger bei der Verwirklichung des Traums von den eigenen vier Wänden zu unterstützen und damit auch einen Beitrag zu deren Altersvorsorge zu leisten. ${ }^{3}$

2 Die Angaben sind der Tabelle 2 in Gorton, Gary, European Financial Management 15,2009, S. 14 entnommen. Die dort angeführten Beträge in „Billions“ sind hier in Tabelle 1 in der üblichen deutschen Schreibweise als Milliarden \$ ausgewiesen. Der in der Tabelle ausgewiesene Bruttozugang misst die Neuemissionen abzüglich der in dem betreffenden Jahr erfolgten Tilgungen.

$3 \mathrm{Zu}$ Einzelheiten vgl. European Economic Advisory Group, The EEAG Report on the European Economy 2009, CESifo München 2009, S. 60 ff. 
Tabelle 1: Anteile der Agency- und Non Agency-Kredite am Markt für MBS

\begin{tabular}{|l|l|l|l|l|l|l|}
\hline \multirow{2}{*}{ Jahr } & \multicolumn{5}{|l|}{ Volumen und Bruttozugang an Mortgage Backed Securities in Mrd. US\$ } \\
\cline { 2 - 7 } & Agency MBS & \multicolumn{3}{|l|}{ Non-agency MBS } & \multicolumn{3}{l|}{ Total MBS } \\
\cline { 2 - 7 } & Bestand & Bruttozugang & Bestand & Bruttozugang & Bestand & Bruttozugang \\
\hline 2000 & 2.625 & 479 & 377 & 135 & 3.003 & 615 \\
\hline 2001 & 2.975 & 1.090 & 434 & 267 & 3.409 & 1.357 \\
\hline 2002 & 3.313 & 1.440 & 489 & 414 & 3.802 & 1.854 \\
\hline 2003 & 3.394 & 2.130 & 611 & 586 & 4.005 & 2.716 \\
\hline 2004 & 3.467 & 1.020 & 1.014 & 865 & 4.481 & 1.885 \\
\hline 2005 & 3.608 & 965 & 1.593 & 1.191 & 5.201 & 2.156 \\
\hline 2006 & 3.905 & 925 & 1.924 & 1.146 & 5.829 & 2.071 \\
\hline
\end{tabular}

\section{Problematische Trends und Exzesse seit der Jabrbundertwende}

Nach der Jahrhundertwende und insbesondere seit dem Zusammenbruch der New Economy Blase 2002 traten am amerikanischen Markt für Wohnimmobilien Besonderheiten auf, die in verschiedener Hinsicht als problematisch eingestuft werden müssen. So trug die Bevorzugung der Küstenregionen mit einem hohen Hauspreisniveau und großen Wohnungen zu den hohen Preissteigerungen bei, die letztlich in eine ausgeprägte Immobilienpreisblase (Bubble) mündeten. In diesem Zeitraum konnte man auch eine Ausweitung der privaten Hypothekenfinanzierung feststellen, die im Zusammenhang mit der hohen Marktliquidität zu sehen war, die ihrerseits durch das niedrige Zinsniveau begünstigt wurde. Das niedrige Zinsniveau seinerseits wurde nach dem Zusammenbruch der New Economy von der Politik der amerikanischen Zentralbank, der Federal Reserve, durchgesetzt bzw. gestützt. Die Kreditvergabe selbst erfolgte während dieser Zeit zunehmend über die Vermittlung einer großen Schar von Maklern, die mit ihren abschlussorientierten Vergütungen einen Anreiz hatten, auch bonitätsschwache Kaufinteressenten zu einer Kreditaufnahme und dem Kauf einer Wohnimmobilie zu bewegen.

Die Finanzierung der Wohnungsbaukredite erfolgte nach der Jahrhundertwende vielfach auch oberhalb der staatlichen Fördergrenzen durch private Institutionen (Jumbo Kredite). Die sonst übliche Anforderung an einen Eigenkapitalanteil am Wert der Wohnimmobilie in Höhe von mindestens $20 \%$ wurde aufgeweicht bzw. ganz fallen gelassen. Wegen des niedrigen Zinsniveaus gab es eine Bevorzugung der Kreditverträge mit Gleitzinsen bzw. variablen Zinsen. Schließlich wurde Wohneigentum auch für Bezieher sehr niedriger Einkommen oder sogar Personen ohne geregeltes Einkommen und zweifelhafter Bonität verfügbar. Diesen Kreditnehmern, die häufig bereits anderweitig verschuldet und ihren Zahlungsverpflichtungen nicht pünktlich nachgekommen waren, wurden als Subprime Mortgages bezeichnete Kredite zur Verfügung gestellt, deren Werthaltigkeit aus der Sicht der Kreditgeber letztlich auf den antizipierten Preissteigerungen der Wohnimmobilien be- 
ruhte. Der Begriff Subprime Mortgage bezeichnete dabei keine gesetzlich definierte Kategorie von Hypothekarkrediten, sondern war ein Sammelbegriff für Kredite für Wohnimmobilien an Kreditnehmer geringer Bonität mit hohen Zahlungsverpflichtungen (Debt Payment-to-Income Ratio) und/oder einer hohen Beleihungsquote (Mortgage Loan-to-Value Ratio) des Immobilienbesitzes. ${ }^{4}$ Das nach den Subprime Mortgages qualitativ zweitschlechteste Marktsegment bildete das Alt-A-Segment, das in den Jahren um 2004 das stärkste Wachstum verzeichnen konnte. Dabei handelt es sich um Kredite an Schuldner mit einer Bonität, die derjenigen erstklassiger Schuldner durchaus nahe kommt. Den Schuldnern mangelt es aber an der Erfüllung anderer Bedingungen für eine erstklassige Bewertung, weil sie beispielsweise keinen zeitnahen Einkommensnachweis vorlegen können oder die Art der Immobilie als Sicherungsgrundlage nicht den gängigen Anforderungen entspricht. ${ }^{5}$

Da die Hauspreise über lange Jahre stabil gestiegen waren und daher der Wertgewinn der Immobilien als gut prognostizierbar galt, wurden weder die Jumbo und Alt-A Kredite, noch die Subprime Kredite als besonders risikoträchtig eingestuft. Festzustellen war auch ein wachsender Anteil der computergestützten Bereitstellungen von Hypothekendarlehen, die sich auf ein einfaches Rating (FICO Score) stützten und zu einer Konzentration der Kreditvergabe bei den großen Hypothekeninstituten beitrugen. ${ }^{6}$ Bei sinkenden Hypothekenzinssätzen lohnte es sich darüber hinaus für die Schuldner, von der Option einer vorzeitigen Tilgung und Erneuerung der Hypothekendarlehen Gebrauch zu machen, sobald eine Wertsteigerung eingetreten war oder sich eine weitere Zinssenkung durchgesetzt hatte, so dass die Schuldner ihre Kreditfinanzierung ausweiten konnten. Schließlich konnten sich die Kreditnehmer, falls sie ihren Verpflichtungen nicht nachkommen konnten, durch Rückgabe der Immobilie an die Bank ihrer Zahlungsverpflichtungen entledigen („Jingle Mails“ als Ausdruck der Haftungsbeschränkung auf das Wohnobjekt). Von 2002 bis 2005 stieg der Anteil variabel verzinslicher Hypothekenkredite von ca. $15 \%$ auf $40 \%$ des Marktvolumens. Der kurzfristige Zins lag seit 1999 bis 2006 dabei stets deutlich unter dem

4 Vgl. die ausführliche Beschreibung der Kategorien typischer Bonitätsstufen von Mortgages bei Gorton, European Financial Management 15 (2009), S. 12. Chomsisengrhet, Souphala/Pennington-Cross, Anthony, Federal Reserve Bank of St. Louis Review 88, Jan-Feb 2006, S. 31-56, vom Office of the Comptroller of the Currency und der Federal Reserve Bank of St. Louis zeichnen die Entwicklung des Subprime Mortgage Market seit Mitte der 1990er Jahre ausführlich nach und stellen (in der Diktion vorwurfsvoll) fest, dass sich der Markt in der zweiten Boomperiode von 2000 bis 2004 auf die besseren Kreditqualitäten konzentriert hat und Kreditnehmer mit niedrigem Rating „still pay the largest premiums.“ (S. 55).

5 Vgl. Frankel, Allen, BIZ-Quartalsbericht, März 2006, S. 75, S. 77.

6 Die Werte des Fair Isaac \& Co Inc. Credit Scorings variieren zwischen 300 bis 900. Während für den Prime Markt Werte über 700 gefordert werden, sprechen Score Werte unter 620 (500 bis 660) für einen Subprime Kredit. 
längerfristigen Zins, so dass es für die Kreditnehmer einen Anreiz gab, sich variabel verzinslich zu verschulden.

Unter den geschilderten Voraussetzungen wurden auch an Kreditnehmer Darlehen vergeben, die über keine feste Einkommensquelle und keinen Eigenkapitalbeitrag verfügten, sog. Ninjas (No Income, No Job or Assets). Bemerkenswert waren so genannte $2 / 28$ oder $3 / 27$ Kredite mit einem niedrigen Lockzinsangebot (Teaser Rate) und dem Verzicht auf eine Tilgung innerhalb der ersten zwei oder drei Jahre. Danach waren eine normale Tilgung über 28 bzw. 27 Jahre sowie variable Zinsen vorgesehen, wobei die Kreditnehmer und Kreditgeber auf weiterhin niedrige Zinsen und steigende Immobilienpreise setzten. Bei Interest-Only Darlehen wurde der Tilgungsbeginn bis zu 10 Jahre ausgesetzt, bei Adjustable Rate Mortgages ein sehr niedriger Anfangszins vereinbart, dem dann eine Zeitspanne mit halbjährlicher Zinsanpassung an einen variablen Zinssatz folgte. Da die Zukunftsaussichten günstig erschienen, setzten sich auch Huckepack-Kredite (Piggybacks) privater Banken durch, die für Konsumzwecke vergeben wurden und die Differenz zwischen der antizipierten Hauspreissteigerung und der Belastung des Grundstücks in verfügbare Zahlungsmittel umsetzten. Negative Amortisationen waren also an der Tagesordnung und schienen kein Problem zu sein, da der Anstieg der Schulden vom Wertwachstum der Wohnimmobilie übertroffen wurde. Mehrfachverschuldungen einzelner Kreditnehmer resultierten daraus, dass die Kreditnehmer gelegentlich mehr als ein Grundstück bzw. eine Immobilie erwarben und darüber hinaus bei ihren Kreditkartengesellschaften oder einem Leasinggeber Außenstände aufbauten.

Dieser Trend zum Erwerb von Wohneigentum wurde auch von offizieller Seite nicht nur kritisch eingeschätzt. So findet man beispielsweise in einem Bericht der BIZ vom September 2002 den Hinweis, dass aus längerfristiger Sicht der jüngste Refinanzierungsboom auf eine neue Welt hinweisen könnte, „in der Wohneigentum zunehmend als Liquiditätsquelle betrachtet und zum Ausgleich bei Schwankungen bei Einkommen und Vermögen eingesetzt wird."

\section{Die Märkte für Mortgage Backed Securities}

Typisch für die Finanzierung von Wohnimmobilien ist am amerikanischen Markt die Weitergabe der Kreditpositionen bzw. der mit den Kreditpositionen verbundenen Ausfallrisiken über verschiedene Kreditrisikotransferinstrumente an die Märkte für strukturierte Anleihen und die Platzierung dieser Anleihen bei institutionellen Investoren (Securitisation). Die Errichtung eines Sekundärmarktes für Kreditrisiken ist insbesondere durch die Government Sponsored Enterprises Fannie Mae und Freddie Mac ermöglicht und durch

7 Deep, Akash/Domanski, Dietrich, BIZ-Quartalsbericht, Sept. 2002, S. 42 ff, S. 50. 
deren Garantieübernahmen begünstigt worden. Neben diesen früher halbstaatlichen Agenturen haben aber auch Investmentbanken und Mortgage Bankers als Arrangeure Hypothekarkredite aufgekauft, gebündelt und auf Zweckgesellschaften übertragen, die über diese Forderungspools strukturierte Schuldverschreibungen (MBS) ausgegeben haben.

Die Konstruktion der MBS folgt dabei i.d.R. dem Pay-Through Modell, bei dem keine bloße Durchleitung der eingehenden Zins- und Tilgungszahlungen wie bei den Pass-Through Papieren erfolgt, sondern bei dem die eingehenden Cashflows nach vordefinierten Verteilungsschlüsseln den verschiedenen Anleihetranchen zugeordnet werden. Typisch ist bei Pay-Through-Konstruktionen die Zerlegung des Gesamtpools in Risikoschichten nach einem Wasserfallprinzip der Verluste (Subordinationsprinzip), das zu unterschiedlich risikobehafteten Tranchen der Inhaber der MBS führt. Die so konstruierten Asset Backed Securities werden als Collateralized Loan Obligations (CLOs) bezeichnet und basieren entweder als True Sale CLOs auf Pools von Hypothekenforderungen oder als synthetische CLOs auf Pools aus Staatsanleihen und Kreditderivaten, wobei letztere in der Regel in der Form von Credit Default Swaps (CDS) nur das Ausfallrisiko von Kreditportfolios, nicht aber die Kreditpositionen selbst transferieren. ${ }^{8}$ Abbildung 1 verdeutlicht die Grundkonstruktion einer True-Sale-Transaktion, Abbildung 2 die Idee des Subordinationsprinzips.

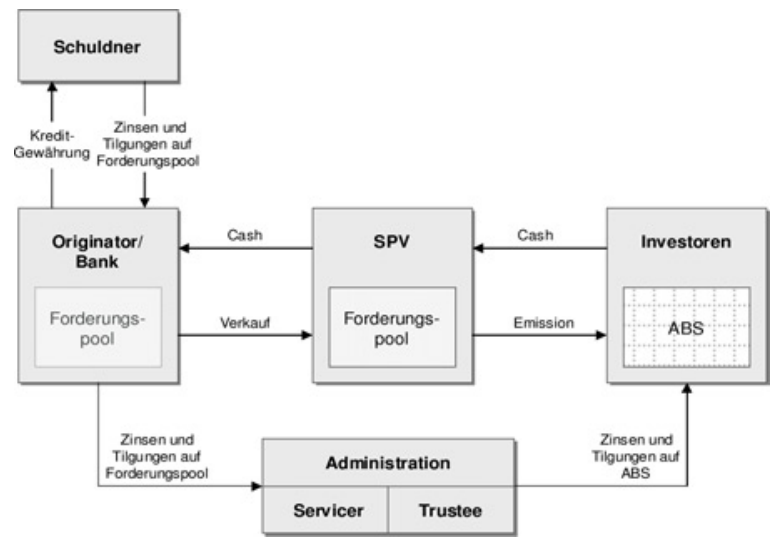

Abb. 1: Grundstruktur einer True-Sale-Verbriefung

Das Zusammenführen der Kredite (Poolen) und das Strukturieren der Kreditforderungen (Tranchieren) erfolgt in einer nur zu diesem Zweck einge-

8 Die mit Kreditforderungen unterlegten Collateralized Loan Obligations CLOs stellen ebenso wie die Collateralized Bond Obligations CBOs, die mit Anleihen unterlegt sind, einen Teilmarkt der Collateralised Debt Obligations CDOs dar. Vgl. zu einer Einordnung Rudolph et al., aaO (Fn. 1), S. 40. 
richteten Zweckgesellschaft, einem Special Purpose Vehicle (SPV). Das SPV nimmt eine vom Originator insolvenzferne Position ein, damit die Inhaber der strukturierten Papiere einerseits ausschließlich Ansprüche gegen die Zweckgesellschaft geltend machen können, andererseits aber von einer möglichen Insolvenz des Originators der Kredite nicht betroffen sind, weil ihre Forderungen gegen ein Sondervermögen gerichtet sind, das nicht in die mögliche Insolvenzmasse des Originators fällt. An die Zweckgesellschaft, die von dem Arrangeur gemanagt und von einem Treuhänder (Trustee) überwacht wird, werden vom Originator einmalig oder revolvierend Kredite abgetreten (True Sale CLOs) bzw. bei synthetischen CLOs Kreditrisiken über Credit Default Swaps übertragen. Auf der Grundlage dieses Kreditpools werden dann die Asset Backed Securities ausgegeben, wobei eine signifikante Streuung der Risiken im Pool und eine gewisse Übersicherung (Credit Enhancement) die Qualität der Emission steigern. Die Zweckgesellschaft ihrerseits emittiert die ABS - insbesondere bei inhomogenen Pools - in Form von Collateralized Debt Obligations (CDOs). ${ }^{9}$ Der Treuhänder überwacht die Verteilung und Weiterleitung der aus den Poolforderungen eingegangenen Zins- und Tilgungszahlung an die Inhaber der verschiedenen Tranchen. Der ökonomische Zweck der Special Purpose Vebicles (SPVs) besteht für die Inhaber der ABS bzw. CDOs insbesondere in der Isolierung eines bestimmten Risikobereichs durch Zusammenlegung der Forderungen in den Pool, durch die Abkopplung des Kreditrisikos des Forderungspools vom Kreditrisiko des Originators und durch das Tranchieren der Schuldverschreibungen, die durch den Pool von Krediten gedeckt sind..$^{10}$ Aus ökonomischer Perspektive lässt sich zeigen, dass solchermaßen konstruierte Kreditrisikotransferinstrumente zur Vervollkommnung der Kapitalmärkte, zu ihrer Vervollständigung und zur Verbesserung der Informationseffizienz der Märkte beitragen können. ${ }^{11}$

Die Technik des Poolens und Tranchierens ist mit verschiedenen Vorteilen verbunden, weil Finanzinstrumente konstruiert werden können, die genau auf den „Risikoappetit“ verschiedener Anlegergruppen bzw. sogar einzelner Anleger zugeschnitten sind. ${ }^{12}$ Mit Hilfe strukturierter Anleihen lassen sich

9 Der den CDOs zugrunde liegende Asset-Pool beinhaltet häufig nur wenige Kredite und darüber hinaus unterschiedliche Arten von Forderungen. Insoweit wird er als inhomogen bezeichnet.

10 Vgl. Fender, Ingo/Mrtchell, Janet, BIZ-Quartalsbericht, Juni 2005, S. 77 ff, S. 79. Vgl. auch Gorton, Gary B./Souleles, Nicholas S., in: M. Carey/R. Stulz (Hrsg.), The Risks of Financial Institutions, 2006, S. 549-597, die als wesentliches Ziel der Konstruktion von SPVs die Ersparnis möglicher Insolvenzkosten herausarbeiten.

11 Vgl. Rudolph, Kredit und Kapital 40, 2007, S. 2 ff sowie zu einer ausführlichen modellgestützten Abwägung der Vor- und Nachteile der neuen Märkte Dufrie, Darrell, BIS Working Paper No. 255, 2008.

12 Diese immer wieder als Vorteil betonte Möglichkeit hat sich später in der Krise als Nachteil herausgestellt, weil die so strukturierten Instrumente keinen liquiden Sekundärmarkt bilden konnten. 


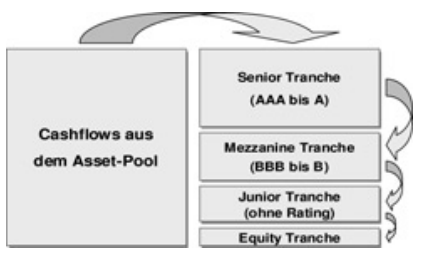

Abb. 2: Grundprinzip des Subordinations- oder Wasserfallmechanismus

also Risiken nicht nur transferieren, sondern auch in ihrer Qualität transformieren.

Der Mehrwert der Poolbildung besteht insbesondere im Diversifikationseffekt, der allerdings für die Anleger mit einer Informationsvernichtung einhergeht. ${ }^{13}$ Die in den Pool eingebrachten Kredite sind mit Zinssätzen versehen, die auf der Basis ihrer individuellen Bonität kalkuliert worden sind. Durch die Diversifikation erhält der Pool eine höhere Qualität und damit ein besseres Rating als das durchschnittliche Rating der Einzelkredite.

Der Mehrwert der Subordination durch Tranchenbildung resultiert insbesondere daraus, dass einerseits informationsinsensitive, quasi risikofreie bzw. risikoarme Wertpapiere konstruiert werden können, die wegen ihres niedrigen Risikos an nicht professionelle Anleger bzw. Anleger mit strengen Anlagekriterien abgegeben werden können, sowie andererseits informationssensitive, höher verzinsliche risikobehaftete Wertpapiere, für die spezialisierte Anleger (z.B. Hedgefonds) eine Präferenz haben, die geringeren Anforderungen entsprechen müssen, im Gegenzug aber häufig mehr Informationen über die Poolqualität zur Verfügung gestellt bekommen. ${ }^{14}$

Schließlich kann die besonders risikobehaftete Tranche, das First Loss- oder Equity- Piece, das regelmäßig die Kreditausfälle in Höhe ihres Erwartungswertes abdecken bzw. sogar überdecken soll, im Portfolio des Originators verbleiben, damit mögliche Anreizprobleme vermindert bzw. abgebaut werden. Damit soll beim Originator das Interesse an einer sorgfältigen Auswahl und Kontrolle der Kreditnehmer trotz der Weitergabe der Risiken erhalten bleiben. ${ }^{15}$ Ein Selbstbehalt des eingetretenen Schadens gilt bekanntlich im Versicherungsgeschäft als wirksames Mittel zur Begrenzung von Moral Hazard- und Adverse Selection-Problemen.

13 Vgl. hierzu die Modellbildung bei DeMarzo, Peter M., The Review of Financial Studies 18, 2005, S. 1-35, der die mit dem Pooling verbundenen negativen Informationsvernichtungs- und positiven Diversifikationseffekte gegenüberstellt und analysiert. Vgl. zur ökonomischen Rationalität des Tranchenbildung auch Rudolph, Bernd/Scholz, Julia, Bank Archiv 55 (2007), S. 538-548.

14 Vgl. Boot, Arnoud W. A./Thakor, Anjan V., Journal of Finance 48 (1993), S. 13491378; Riddiough, Tiмотнy J., Journal of Financial Intermediation 6 (1997), S. 121-152; Plantin, Gulllaume, Tranching, Working Paper, Tepper School of Business, Pennsylvania 2004; De Marzo, aaO (Fn. 13).

15 Vgl. Gorton, Gary B./Pennacchi, George G., Journal of Business 66 (1993), S. 1-27. 
In der Literatur ist verschiedentlich auf mögliche Probleme und Schwächen der neuen Instrumente für den Kreditrisikotransfer hingewiesen worden. ${ }^{16}$ So wurde beispielsweise bereits in einem Beitrag der BIZ vom Juni 2005 argumentiert, dass „Ratings von strukturierten Finanzprodukten zwar nützlich sind, aber wegen inhärenter Unzulänglichkeiten die Risiken dieser Produkte nicht voll erfassen können. “ ${ }^{17}$ Die Autoren wiesen nämlich auf einen wichtigen Unterschied zwischen strukturierten Finanzierungen und anderen Risikotransferprodukten hin. Strukturierte Instrumente transformieren Risiken durch Tranchenbildung in unterschiedliche „Scheiben“ der Verlustverteilung des zugrunde liegenden Forderungspools. Diese Aufteilung in „Scheiben“ und die hierfür erforderlichen vertraglichen Strukturen könnten aber die Einschätzung der Risikomerkmale der einzelnen Tranchen enorm erschweren, so dass Ratings die Risiken tranchierter Wertpapiere nicht vollständig erfassen können. Die Autoren machten darüber hinaus darauf aufmerksam, dass sich die Anleger gerade bei diesen strukturierten Papieren wegen ihrer Komplexität stärker als bei anderen Wertpapieren auf die Ratingurteile der Agenturen verlassen müssten.

Die in den Jahren vor der Subprime Krise publizierten wissenschaftlichen Beiträge konnten auch andere Probleme der Märkte für den Transfer von Kreditrisiken u. a. durch Simulationsstudien deutlich machen, die die Messbarkeit und Isolierbarkeit der spezifischen Risiken oder die Informationen über mögliche Änderungen des Risikos im Zeitablauf betrafen. Sobald es nämlich in der Verlusthierarchie eines CDO zu einem Ausfall kommt, verschiebt sich das Risikoprofil über alle nachfolgenden Tranchen hinweg. Und ebenso verschiebt sich das Risikoprofil, wenn sich die makroökonomischen Faktoren verändern, die auf den Risikogehalt des Pools einwirken. ${ }^{18}$ Schließlich verändert sich mit solchen Ereignissen auch die Korrelation der Cashflows mit den Cashflows anderer Finanzinstrumente. Wegen der mangelhaften Abbildung solcher Risikoänderungen ist im Zuge der Finanzmarktkrise die Berechenbarkeit und Transparenz der Risiken tranchierter Produkte generell in Frage gestellt worden. So war beispielsweise die Wirkung des Subordinations- oder Wasserfallprinzips beim Verlustübergang im Prinzip bekannt, der konkrete Umfang der Risiken bei einer Verschiebung der

16 Vgl. beispielsweise die frühen Hinweise in Henke, Sabine, Anreizprobleme beim Transfer der Kreditrisiken aus Buchkrediten, 2002; Rajan, Raghuram G., Federal Reserve Bank of Kansas City, Proceedings, Aug. 2005, S. 313-369.

17 Vgl. Fender/Mitchell, aaO (Fn. 10), S. 77.

18 Vgl. Gann, Philipp, Liquidität, Risikoeinstellung des Kapitalmarktes und Konjunkturerwartung als Preisdeterminanten von Collateralized Debt Obligations (CDOs) Eine simulationsgestützte Analyse, Münchener Wirtschaftswissenschaftliche Beiträge (BWL) 2009-8, Ludwig-Maximilians-Universität München, April 2009. 
Verlustverteilung des ursprünglichen Kreditportfolios aufgrund makroökonomischer Einflüsse aber nur schwer abschätzbar. ${ }^{19}$

Wie die Diskussion der verschiedenen Entwicklungen zeigt, hat im Lauf der Zeit bei der immer weiteren Zerlegung der Wertschöpfungskette der Kreditvergabe, Verbriefung und Refinanzierung der Kredite die Anzahl und Bedeutung der verschiedenen Friktionen zugenommen. Diese Friktionen sind intensiv insbesondere von Ashcraft und Schuermann ${ }^{20}$ herausgearbeitet und danach im Finanzstandortbericht zusammenfassend dargestellt worden. Die dort zu findende Übersicht soll an dieser Stelle noch einmal zur Veranschaulichung herangezogen werden. ${ }^{21}$ Mit „Predatory Lending“ wird in (1) die Übervorteilung unerfahrener bzw. in finanziellen Dingen unzureichend informierter Kreditnehmer durch Banken bezeichnet. In vielen Fällen ist Subprime-Kreditnehmern vermutlich nicht bewusst gewesen, welche Risiken und zeitverzögerten Belastungen sie auf sich genommen haben. Ein potenzieller „Mortgage Fraud“ ergibt sich in (2) aus der Informationsasymmetrie zwischen dem Arrangeur und dem Originator. Für den Originator kann sich ein Anreiz ergeben, zum Nachteil des Arrangeurs mit dem Kreditnehmer zu kooperieren und zum Beispiel Kreditunterlagen zu „schönen“ bzw. zu fälschen. (3) bezeichnet eine weitere erhebliche Informationsasymmetrie hinsichtlich der Darlehensqualität zwischen dem Arrangeur und Dritten (z. B. der Rating-Agentur oder einem Asset Manager). Dies kann zu einer bewussten adversen Selektion führen: Der Arrangeur behält die guten Kredite in seinem Portfolio und verbrieft lediglich die schlechten. Zwischen dem Kreditnehmer und dem Servicer besteht in (4) ein Moral-Hazard-Problem. Um den Wert des beliehenen Objektes zu erhalten, muss der Kreditnehmer u. a. Reparaturen, Versicherungen und Steuern zahlen. Gerät er in finanzielle Not und wird das Darlehen zahlungsrückständig, besteht grundsätzlich für den Kreditnehmer kein Anreiz, diese Zusatzverpflichtungen weiter zu erfüllen.

19 Krahnen, Jan Pieter/Wilde, Christian, Risk Transfer with CDOs and Systemic Risk in Banking, Working Paper No. 2006/04, Center for Financial Studies, 2006 weisen im Rahmen ihrer Simulationsstudien nach, dass Tranchen verschiedener CLO-Emissionen, aber gleicher Kreditqualität, eine sehr hohe Korrelation aufweisen, und dass dies auch für die Senior Tranche gilt. Die Korrelationen sind insbesondere von Marktrisikofaktoren abhängig, deren Eintritt die Qualität der Senior Tranchen zahlreicher Emissionen betreffen kann. Sehr aufschlussreiche Ergebnisse umfangreicher Simulationsstudien werden auch in Krahnen, Jan Pieter/Wilde, Christian, Risk Transfer with CDOs, Working Paper No. 2008/15, Center for Financial Studies, 2008, abgeleitet, wo die Simulationen insbesondere die besonders ausgeprägte Zunahme des Risikos der hochwertigsten Tranche bei Eintritt eines gesamtwirtschaftlichen Schocks zeigen.

20 Ashcraft, Adam B./Schuermann, Til, Understanding the Securitization of Subprime Mortgage Credit, Federal Reserve Bank of New York, Staff Report No. 318, 2008.

21 Die Darstellung ist entnommen aus: Initiative Finanzstandort Deutschland, Finanzstandort Deutschland Bericht Nr. 4, 2008, S. 103. Die folgende Erläuterung der Darstellung lehnt sich an diese Quelle an. 
Zwischen dem Servicer, der Rating-Agentur und dem Asset Manager besteht in (5) ebenfalls ein Moral-Hazard-Problem. Für den Servicer ist es grundsätzlich vorteilhaft, die Zwangsvollstreckung aus einem ausgefallenen Darlehen herauszuzögern, da er umso mehr Provision verdient, je länger er das Darlehen administriert. Verzögerungen bei der Verwertung mindern jedoch regelmäßig den Wert des Beleihungsobjektes und den zu erwartenden Verwertungserlös. Im Fall einer CDO tritt noch ein (6) Principal-Agent- Problem zwischen Investor und Asset Manager hinzu. Der Investor (Principal) stellt finanzielle Mittel zur Verfügung. Ihm fehlt jedoch Zeit, Infrastruktur und Expertise, um ein Portfolio selbst zusammenzustellen, weshalb er die Aufgabe einem Asset Manager (Agent) überträgt, der nicht zwangsläufig überwiegend im Interesse des Investors agiert. Zwischen Investor und Rating-Agentur besteht letztlich noch ein Spannungsverhältnis, das als (7) „Modell-Irrtum“ oder potenzieller Interessenkonflikt aufgefasst werden kann. Die Modelle der Rating-Agenturen sind dem Investor nicht vollständig transparent, so dass sich eine starke Abhängigkeit ergibt. Zum Teil wird auch zu viel in das Rating hineininterpretiert, es entsteht ein „Expectation Gap“. Statt als Meinung über Ausfallrisiko wird ein Rating häufig auch als Aussage über zu erwartende Liquidität und Marktpreis(stabilität) ausgelegt und auf entsprechende eigene Analysen verzichtet.

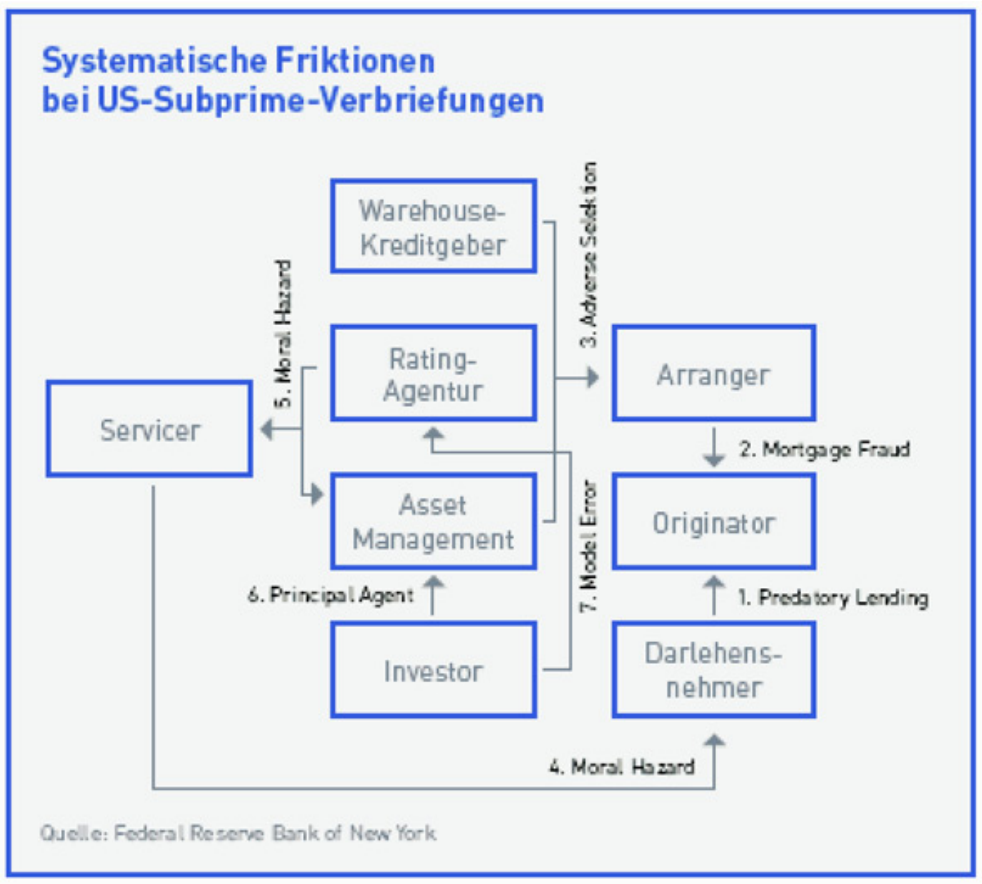

Abb. 3: Überblick über wichtige Friktionen bei US-Subprime-Verbriefungen 
Eine bemerkenswerte Besonderheit des dargestellten Kreditvergabe- und Refinanzierungsprozesses, die vor der Subprime Krise in den publizierten Beiträgen weitgehend übersehen oder nicht untersucht worden war, bestand in der zusätzlichen Variante des Geschäftsmodells, dass ein beachtlicher Teil der im Zuge des Kreditrisikotransfers von den Banken an die Kapitalmärkte abgegebenen Kreditrisiken in Form strukturierter Anleihen (Tranchen von CDOs) indirekt oder direkt wieder in ihre eigenen Bücher zurück gewandert war. Mit der Absenkung der Diskontrate nach dem Ende der „New Economy Bubble“ zur Abfederung der Wirtschaft gerieten nämlich viele institutionelle Anleger und Banken in einen „Anlagenotstand“, weil den hohen Renditeerwartungen der Anleger wegen des niedrigen Zinsniveaus nur magere Ertragsmöglichkeiten entgegenstanden. In dieser Situation befanden sich Investmentbanken, Geschäftsbanken, internationale und regionale, private und staatliche Banken, die einen Ausweg aus dem Ertragsdilemma suchten, indem sie entweder selbst durch entsprechende Investments oder über das Betreiben separater Anlagevehikel (Conduits und Structured Investment Vehicles SIVs) in die am Markt umlaufenden CDOs und Credit Linked Notes mit erstklassigem Rating investierten. ${ }^{22}$ Diese Produkte versprachen eine höhere Rendite als andere, mit dem gleichen Rating versehene „normale“ Anleihen.

Die später in der Krise sich als fatal herausstellende Geschäftsaktivität vieler Banken bestand im Kern darin, Conduits oder Structured Investment Vehicles $(S I V s)$ zu betreiben, die einerseits in CDOs und andere strukturierte Assets Produkte mit hohen Ratings investierten und sich andererseits durch die Ausgabe von Asset Backed Commercial Paper (ABCP) refinanzierten.

Die hoch gerateten Assets (ABS und CDO) und Kreditderivate (Credit Default Swaps CDS) mit langer Laufzeit, die durch die Pools aus Krediten mit vergleichsweise niedrigem Rating gedeckt waren, wurden von den Anlage-

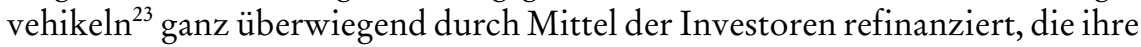
Mittel kurzfristig durch den Kauf von quasi „risikofreien“ Commercial Paper zur Verfügung stellten. Zur Realisierung dieses hohen Leverage benötigten sie erstens ein hohes Rating des Conduits oder SIV und zweitens eine Liquiditätszusage des Sponsors. Zugleich mit der Abschöpfung des „CDO-Aufschlags" konnten damit im Zuge einer starken Fristentransformation und das damit verbundene „Riding the Yield Curve“ über die Anlagevehikel erstens Erträge aus dem Leverage Effekt, zweitens aus der Fristentransformation und drittens aus der Risikotransformation realisiert werden. Da die Conduits in

22 Bei Credit Linked Notes vermindern sich die Zins- oder Tilgungszahlungen beim Eintritt von Kreditereignissen im Sicherheitenpool. Ihnen liegt also kein True Sale, sondern eine Risikoübertragung mit Hilfe von Kreditderivaten zugrunde.

23 Die Conduits und SIVs wurden vom Sachverständigenrat bezeichnenderweise als „Quasi-Banken“ bezeichnet. Vgl. Sachverständigenrat zur Begutachtung der gesamtwirtschaftlichen Entwicklung, Das Erreichte nicht verspielen, Jahresgutachten 2007/8, 2007, S. 89. 


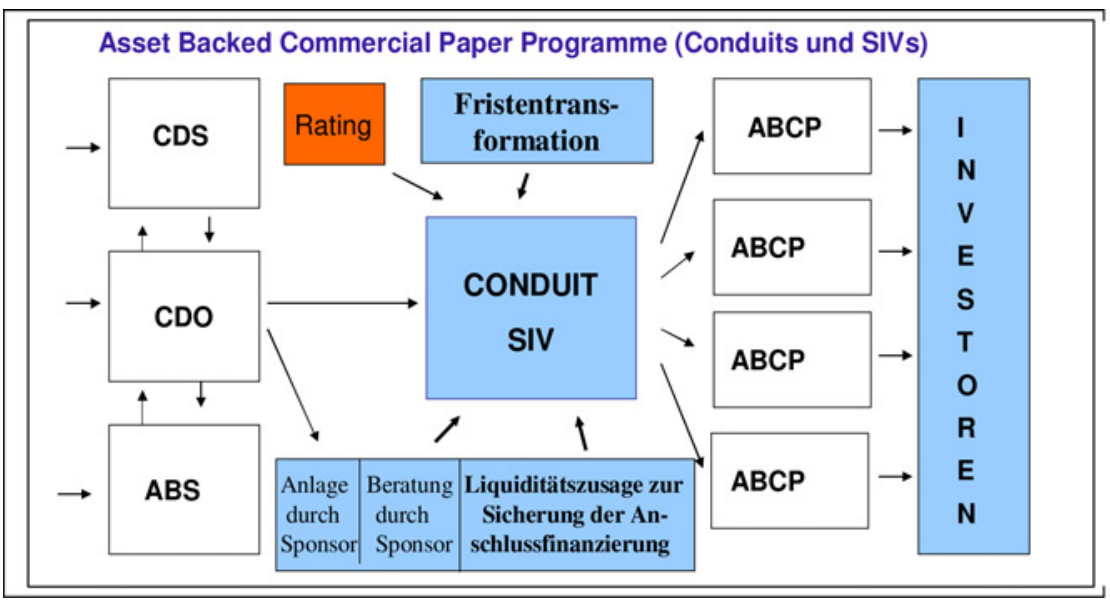

Abb. 4: Struktur eines Asset Backed Commercial Paper Programms

der Regel so konstruiert waren, dass sie zumindest regulatorisch (und z.T. wohl auch ökonomisch) kein Eigenkapital vorhalten mussten, konnte bis zum Eintritt der Krise mit einem sehr großen Hebel gearbeitet werden. ${ }^{24}$

Ein kritischer Punkt dieser Konstruktion war natürlich die Absicherung der Inhaber der Commercial Paper, die nach Ablauf ihres Anlagezeitraums von beispielsweise drei Monaten die Gewähr haben mussten, dass sie ihre CP bei Fälligkeit einlösen konnten. Diese Absicherung wurde neben einem hervorragenden Rating durch Kredit- oder Liquiditätslinien erreicht, die die Kreditinstitute als Sponsoren den Anlagevehikeln zur Verfügung stellten. ${ }^{25}$ So schreibt die IKB in ihrem Geschäftsbericht 2006/2007, dass innerhalb des

$24 \mathrm{Da}$ die Conduits als spezielle insolvenzferne Zweckgesellschaften aufgestellt sind, gehören sie nicht zum Konzernbereich der Kreditinstitute und werden dementsprechend auch nicht konsolidiert. Die Kreditinstitute treten als Berater auf und werden auch, da sie nicht Eigentümer der Conduits sind, über Beratungshonorare vergütet. Adelson, Mark/Jaсов, David, The Sub-prime Problem: Causes and Lessons, Working Paper, 2008 vertreten die Auffassung, dass diese Privilegierung und die damit verbundenen günstigen Finanzierungsmöglichkeiten ein wichtiger Anstoß zur Aufweichung der Kreditstandards der Originatoren der Kredite waren. In die CDO-Pools konnten nämlich auch qualitativ minderwertige Kredite aufgenommen, ohne dass dies die Emissionsbedingungen der verschiedenen Tranchen entscheidend verschlechterte.

25 Conduits waren im Allgemeinen in hoch geratete ABS und Tranchen strukturierter Wertpapiere (CDO) investiert. Da sie sich über die Ausgabe kurz laufender Commercial Paper refinanzierten, benötigten sie ein erstklassiges Rating. Eine ähnliche Struktur weisen die sog. SIVs (Structured Investment Vehicles) auf, die sich zusätzlich durch die Ausgabe von Medium Termin Notes mit einer Fristigkeit von 1 Jahr bis 3 Jahre sowie von Capital Notes (Nachrangpapiere mit höherer Verzinsung und höherem Risiko als ABCP) mit Gewinnbeteiligung refinanzieren konnten. Gemeinsam sind beiden Konstruktionen die Liquiditätszusagen der Sponsoren im Falle von Marktstörungen über Ankaufs- bzw. Refinanzierungsgarantien. 
Conduits „Rhineland-Funding“ eine Laufzeitarbitrage zwischen mittel- bis langfristigen Aktiva und kurzfristiger Refinanzierung mit entsprechenden Margenvorteilen bei den Funding-Kosten verwirklicht worden sei. Demgegenüber wären Zinsrisiken über den Abschluss von Zinssicherungsgeschäften grundsätzlich ausgeschlossen worden. ${ }^{26}$ Die plötzliche massive Inanspruchnahme der Kredit-bzw. Liquiditätslinien nach den Herabstufungen der Assets durch die Ratingagenturen wurde für die Sponsoren der Conduits und SIVs in der Krise zur „Falle“.

\section{Von der Subprime Krise zur internationalen Finanzkrise}

$\mathrm{Ab}$ etwa der Jahresmitte 2006 traten verstärkt Risiken in das Bewusstsein verschiedener Anleger, die daraus resultierten, dass erstens das Zinsniveau langsam stieg, ${ }^{27}$ dass zweitens dadurch bedingt die Ausfallraten im Subprime Segment der Wohnungsbaufinanzierung anstiegen und dass drittens die über lange Zeit gewohnten jährlichen Hauspreissteigerungen abflachten bzw. ab dem Jahreswechsel 2007 sogar ein Preisverfall zu verzeichnen war. Abbildung 5 zeigt, dass die durchschnittlichen Preissteigerungen im Immobilienbereich viele Jahre lang bis zum Jahresende 2006 zwischen 10-15\% lagen, in 2006 rückläufig waren und etwa seit dem Jahreswechsel $2006 / 2007$ ein Rückgang der Immobilienpreise zu verzeichnen war. ${ }^{28}$

Die wachsenden Probleme, die sich aus der Entwicklung des amerikanischen Marktes für Wohnimmobilien für die Finanzmärkte ergeben konnten, wurden durchaus wahrgenommen, aber ohne Dramatik kommentiert, wie ein Beitrag im vierten Quartalsbericht der Bank für Internationalen Zahlungsausgleich vom Dezember 2006 belegt, der davon ausgeht, dass die Märkte mit „einer sanften Abschwächung“ rechnen. „Die rasche Abkühlung des US-Wohnimmobilienmarktes zog die Aufschläge auf die meisten hypothekarisch gesicherten US-Wertpapiere (MBS) offenbar kaum in Mitleidenschaft - und dies trotz eines stetig steigenden Anteils von Hypothekendarlehen für nicht erstklassige Schuldner an der Unterlegung dieser Wertpapiere." Ein etwas anderes Bild ergab sich jedoch aus dem Verlauf der ABX.HE-Indizes, einer Gruppe synthetischer Indizes für mit US-Wohnimmobilienkrediten unterlegte Wertpapiere, die die Cashflows von Verbriefungstranchen nicht erstklassiger "Subprime" US-Wohnimmobilienkredite abbilden. Die Entwicklung dieser

26 IKB, Geänderter Geschäftsbericht 2006/2007, 2007, S. 17.

27 Die Fed erhöhte von Mitte 2004 bis Mitte 2006 den Leitzins von 1\% auf 5,25\%, woraufhin auch die Hypothekenzinsen um rund 1,5\% stiegen.

28 Die Abbildung ist dem Jahresgutachten 2008/2009 des Sachverständigenrates entnommen. Vgl. Sachverständigenrat zur Begutachtung der gesamtwirtschaftlichen Entwicklung: Die Finanzkrise meistern - Wachstumskräfte stärken, Jahresgutachten 2008/ 09, 2008, S. 124. 
Indizes zeigt, dass die Wertansätze der Kredite mit den niedrigsten Ratings bereits im Herbst 2006 erheblich zurückgegangen waren, was auf eine stärkere Wahrnehmung der Risiken von Hypothekendarlehen an Schuldner „mit einer nicht makellosen Bonitätsgeschichte" hinweist. ${ }^{29}$

Abbildung 6 zeigt, dass die nach Jahrgangsklassen der Kreditvergabe angeordneten Subprime-Kredite ab 2004 gegenüber den bis 2004 zur Verfügung gestellten Krediten mit dramatisch höheren Ausfallraten behaftet waren. ${ }^{30}$ Ursache für die höheren Ausfallraten waren nicht nur die schlechtere Bonität der neuen Kreditnehmer, sondern, wie Abbildung 7 zeigt, auch die ab 2006 erfolgten hohen Zinsanpassungen der 2004 und 2005 vergebenen SubprimeHypotheken mit sehr niedrigen Teaser Rates. Ein Vergleich mit anderen Klassen von Hypothekenkrediten zeigt darüber hinaus, dass auch im Alt-A Bereich und im Prime Bereich die jüngeren Kredite die höheren Ausfallquoten aufweisen, allerdings auf einem deutlich niedrigeren Niveau. ${ }^{31}$

Als erstes wichtiges Ereignis, das den Beginn der Krise deutlich signalisierte, gilt der Antrag der New Century Financial Corporation, der zweitgrößten Adresse bei der Vergabe von Subprime Mortgages in den USA, auf Gläubigerschutz nach Chapter 11 der amerikanischen Insolvenzordnung am 2. April 2007. Verschiedene Alarmzeichen folgten, die aber von den Marktteilnehmern und der Öffentlichkeit kaum zur Kenntnis genommen wurden. Am 3. Mai 2007 teilte die Schweizerische Großbank UBS nach hohen Verlusten in Subprime Engagements die Schließung des Dillon Read Hedgefonds mit. Es gab Gerüchte, dass auch andere Hedgefonds geschlossen werden müssten. Mitte Juni 2007 erfolgten dann Mitteilungen von Moody's über die Herabstufung von 100 CLOs, die mit Subprime-Krediten unterlegt waren, sowie der Hinweis, dass weitere 250 Anleihen wegen einer möglichen Herabstufung um einen oder mehrere Stufen (Notches) unter Beobachtung gestellt worden seien. Im Juli 2007 wie in den nachfolgenden Monaten fanden bei Moody's wie bei Standard \& Poor's und Fitch massive Herabstufungen statt.

Die Meldungen über die kritische Situation am Markt für strukturierte Wertpapiere, die mit Subprime Hypotheken unterlegt waren, wurden in

29 Hördahl, Peter/Upper, Christian, BIZ Quartalsbericht, Dezember 2006, S. 1 ff, S. 910. Der Beitrag trägt den Titel: „Überblick: Die Märkte rechnen mit einer sanften Abschwächung.“ Die nach unterschiedlichen Ratingkategorien und Kreditvergabezeiträumen gebildeten ABS.HE Indizes (HE: Home Equity) werden von Markit ermittelt, einer 2001 gegründeten internationalen Gesellschaft für Finanzinformationen, die sich insbesondere auf die Bewertung von Kreditrisiken spezialisiert hat.

30 Die Abbildung ist der Expertise des Sachverständigenrates 2008 entnommen. Vgl. Sachverständigenrat zur Begutachtung der gesamtwirtschaftlichen Entwicklung, Das deutsche Finanzsystem. Effizienz steigern - Stabilität erhöhen. Expertise, 2008, S. 127.

31 Beispielsweise beträgt die Ausfallrate für zwei Jahre alte Subprime Kredite des Jahrgangs 2006 ca. $25 \%$, während die für Prime Kredite bei ca. 2 \% liegt. Vgl. International Monetary Fund, Global Financial Stability Report, 2008, S. 12. 


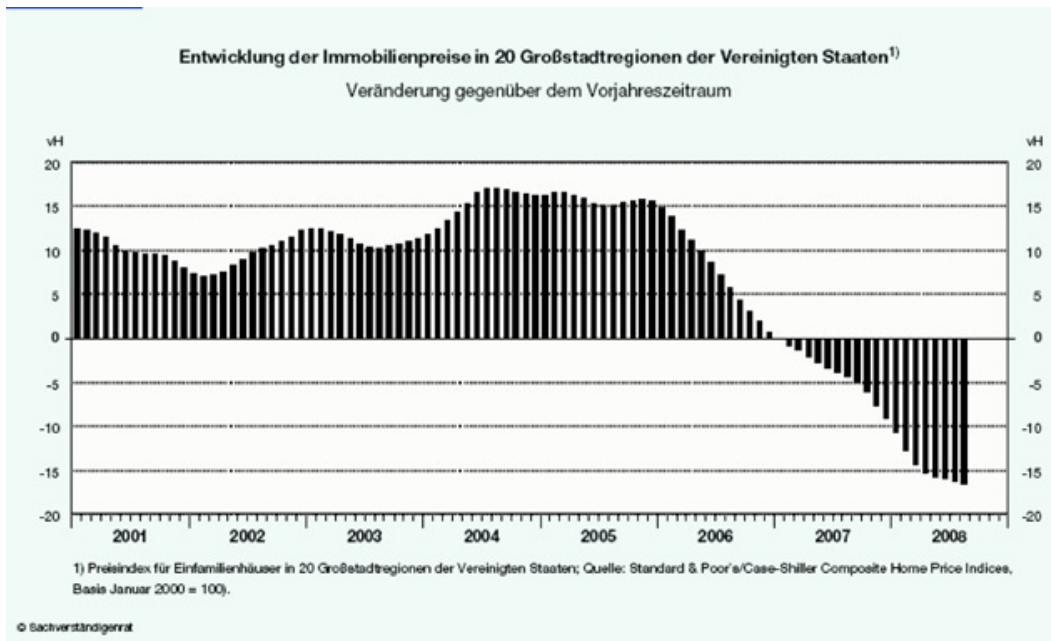

Abb. 5: Entwicklung der Immobilienpreise in den USA

Ausfallraten für Subprime-Hypotheken nach Ausgabejahrgängen 1) Gesamtes Ausgabevolumen $=100 \mathrm{vH}$

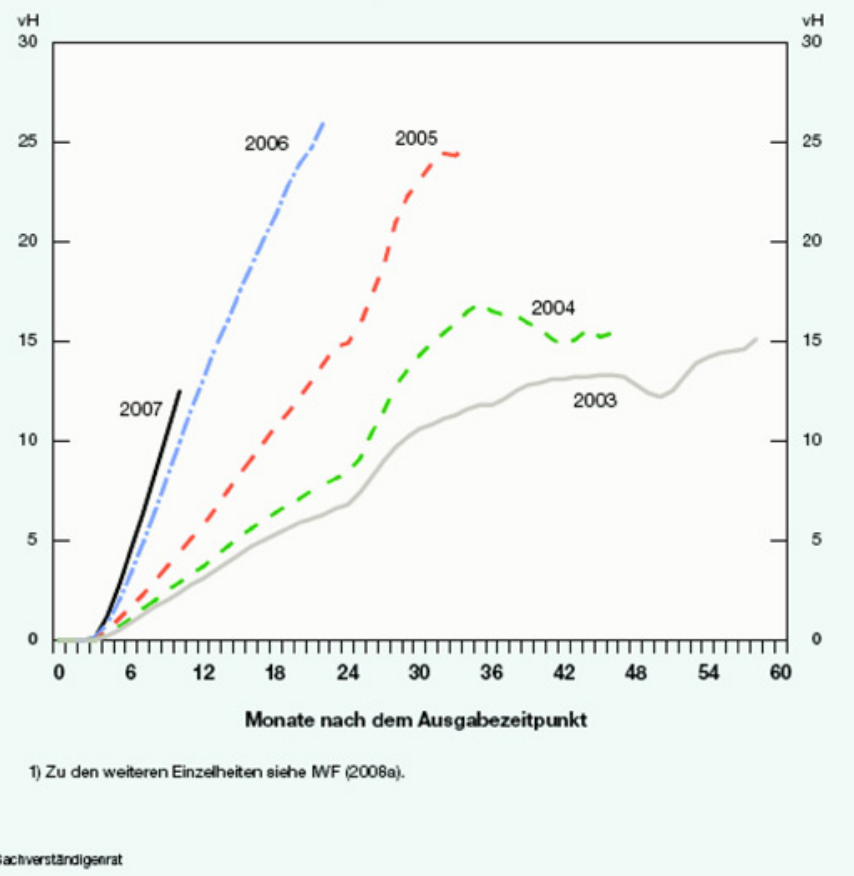

Abb. 6: Ausfallraten von Subprime Krediten unterschiedlicher Vergabeperioden 


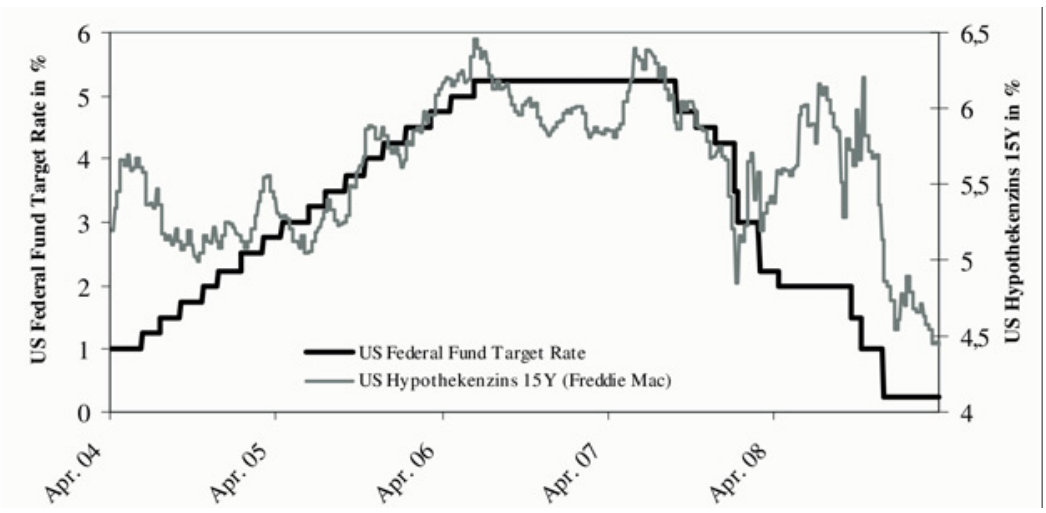

Abb. 7: Zinsentwicklung in den USA vor und während der Finanzkrise

Deutschland nur am Rande verfolgt, bis am 30. Juli 2007 die IKB Deutsche Industriebank in einer Ad hoc Mitteilung hohe Verluste infolge von Problemen an diesem Markt meldete und bekannt gab, dass ihr Hauptanteilseigner, die KfW, ihre finanziellen Verpflichtungen aus den Liquiditätszusagen für eine von ihr betriebene Investmentgesellschaft (Conduit) in den USA, „Rhineland Funding Capital“, übernommen hatte. Die IKB unterhielt - wie andere deutsche und internationale Banken ebenfalls - bereits seit Jahren solche Zweckgesellschaften in den Vereinigten Staaten, die einerseits in langfristige strukturierte Wertpapiere, insbesondere in Collateralized Debt Obligation auf der Basis von Hypothekenforderungen investierten, und die sich andererseits über die Emission kurzfristiger Mortgage Backed Commercial Paper refinanzierten. Diese Form der Finanzintermediation setzte ein hochwertiges Rating des Conduits voraus und dieses seinerseits eine Liquiditätszusage des Sponsors, bei Bedarf die fälligen Commercial Paper einzulösen und die Emission neuer Commercial Paper vorzufinanzieren. Da die zum „Shadow Banking System“ gehörenden Conduits ohne eigenen Eigenkapitalpuffer arbeiteten und die Anlagesummen die Eigenkapitalbasis der Sponsoren um ein Vielfaches übertrafen, verweigerten die Anleger nach dem bekannt gewordenen Wertverfall bonitätsschwacher Kreditforderungen und damit dem Wertverfall von CDOs den Conduits die Anschlussfinanzierung. Die Conduits ließen sich nicht mehr am Geldmarkt refinanzieren, weil den Investoren unklar war, ob die Conduits direkt oder indirekt von dem Wertverfall der Subprime Mortgages selbst betroffen waren. Die Intransparenz der Risikoverteilung auf die verschiedenen Conduits führte dazu, dass die Liquiditätsfazilitäten der Sponsoren in Anspruch genommen werden mussten. Damit wurde aber die Unsicherheit über die Risikoverteilung über die verschiedenen Conduits hinweg zu einer Unsicherheit über die Qualität und Risikotragfähigkeit der Sponsoren. Die für die vorgenommene Fristentransformation attraktive Refinanzierungsquelle des Geldmarktes war versiegt und viele Sponsoren mussten ihre Conduits auf ihre eigenen Bücher nehmen. Da 
nun in rascher Folge die Solvenz der Sponsoren der Conduits selbst in Zweifel gerieten, mussten Auffanglösungen für die Muttergesellschaften gefunden werden.

Die Marktteilnehmer konzentrierten ihr Augenmerk nun auch auf Banken, die möglicherweise oder tatsächlich durch Verluste im Subprime Segment bedroht waren oder bei denen sich die Engagements in anderen Teilen des Kreditmarktes oder an den Märkten für strukturierte Wertpapiere nicht sicher erkennen ließen. Bereits Ende Juli 2007 herrschte an den Interbankenmärkten große Unsicherheit über die Liquiditätslage und die Solvenz der Marktteilnehmer, so dass die Europäische Zentralbank wie andere Notenbanken begann, den Interbankenmärkten in großem Umfang Liquidität zur Verfügung zu stellen. Das Federal Reserve Board verfügte darüber hinaus bereits am 17. August 2007 eine Senkung des Diskontsatzes und kündigte die Bereitstellung neuer Mittel mit einmonatiger Laufzeit an.

Eine bemerkenswerte Eigenheit des Ablaufs der Krise in dieser Phase bestand darin, dass sich viele Kreditinstitute, die direkt in ihren Portfolios oder über ihre Investmentvehikel (Conduits, SIVs) an den Risikoprämien verschiedener Märkte partizipierten, keineswegs ernstlich bedroht fühlten. ${ }^{32}$ Der Grund dafür kann darin gesehen werden, dass in der Zeit von Januar bis Juli 2007 nur $B$ geratete Anleihen und schlechtere Bonitäten von dem Wertverfall betroffen waren, während die hoch gerateten Titel noch keine Einbußen verzeichneten. Abbildung 8 zeigt die Zeitversetzung des Wertverfalls einzelner Ratingklassen und den schließlich einsetzenden Einbruch des amerikanischen Aktienmarktes. ${ }^{33}$ Im Herbst 2007 wurden von großen Banken, anderen Finanzinstituten sowie von den Monoline-Versicherern, die für Asset Backed Trans-

32 So wurden auch bei der Sachsen LB die Marktteilnehmer von der Verlustsituation überrascht, nachdem die Bank noch am 10. August 2007 grundsätzlich keine Anzeichen für eine erhöhte Ausfallwahrscheinlichkeit der von ihrer Tochtergesellschaft Sachsen LB Europe gemanagten ABS-Strukturen gesehen und darauf hingewiesen hatte, dass die Zweckgesellschaft ausschließlich in AAA-geratete ABS Papiere investiert habe und die Bank über ausreichend Liquidität verfüge. Am 17. August musste die Bank allerdings in einer Ad-hoc Meldung mitteilen, dass ein Pool der Sparkassen-Finanzgruppe eine Kreditlinie in Höhe von 17,3 Mrd. € zur Verfügung gestellt und so die Liquidität des Conduits Ormond Quay gesichert habe. Der Sächsische Rechnungshof (2009) hat neben schwerwiegenden Versäumnissen der Führungskräfte und des Verwaltungsrates darauf hingewiesen, dass die Landesbank zu einer Kapitalmarktbank umgebaut worden war und der Anteil der Kapitalmarktaktivitäten am Betriebsergebnis der Bank in den Jahren 2002 bis 2006 durchschnittlich $82 \%$ betrug. Nach Ansicht des Rechnungshofes hätte sich die Bank vorrangig auf die Verfolgung eines wichtigen staatlichen Interesses beschränken müssen. Vgl. Pressemitteilung des Sächsischen Rechnungshofs vom 16. März 2009 zum Sonderbericht nach $\ 99$ SäHO zur Landesbank Sachsen Girozentrale.

33 Die Abbildung ist dem Jahresgutachten 2008/2009 des Sachverständigenrates entnommen. Vgl. Sachverständigenrat (2008/2009), S. 119. 
aktionen die Rückzahlung der emittierten Notes garantierten, Abschreibungen und Quartalsverluste sowie weitere Herabstufungen von CDO-Tranchen gemeldet. Im Frühjahr wurden weitere Quartalsverluste der Banken sowie die Schließung einiger Fonds gemeldet, die durch Hypothekenforderungen gedeckt waren. Die Federal Reserve nahm eine Erhöhung ihrer neuen Term Refinanzierungsmöglichkeiten der Banken, der sog. Term Auction Facilities $(T A F s)$ vor und dehnte ihr Angebot an Wertpapierleihgeschäften durch eine sog. Term Security Lending Facility noch aus. ${ }^{34}$

\section{Die Liquiditätskrise des Jahres 2008}

Der Beginn des Jahres 2008 verlief für die Öffentlichkeit wenig spektakulär, obwohl in dieser Zeit die Bilanzabteilungen der Kreditinstitute weltweit ihr besonderes Augenmerk auf die Bewertung der verschiedenen Anlagen in strukturierten Anleihen richten mussten. Mitte März wurde die Öffentlichkeit von dem Übernahmeangebot für die Investmentbank Bear Sterns durch J. P. Morgan Chase überrascht. Bear Sterns hatte seit Beginn der Krise mit Liquiditätsproblemen zu kämpfen gehabt und war im März 2008 nicht mehr in der Lage, sich am Markt ohne Inanspruchnahme der Zentralbank zu refinanzieren. Mit Unterstützung der Federal Reserve wurde dann Ende Mai 2008 die Übernahme vollzogen. Im Mai kündigten neben der Fed die EZB und die Schweizerische Nationalbank eine nochmalige Ausweitung ihrer Liquiditätshilfen an.

Die Krise erreichte im September 2008 einen Höhepunkt, als Fannie Mae und Freddie Mac wegen hoher Verluste ganz unter Staatsaufsicht gestellt und durch die Federal Housing Agency übernommen wurden. Die Anleihen dieser Government Sponsored Enterprises wurden immer mit einer stillschweigenden Garantie der US-Regierung ausgestattet. Besonders spektakulär und für die weitere Entwicklung besonders dramatisch war dann am 15. September die Verweigerung der Liquiditätshilfe für die Investmentbank Lehman Brothers. Die Verweigerung der Liquiditätshilfe und die damit unvermeidliche Insolvenz von Lehman bewirkten für den gesamten weltweiten Interbankenhandel den Kollaps, weil sich die Kreditinstitute von diesem Zeitpunkt an untereinander selbst kurzfristig keine Mittel mehr ohne spezifische Absicherung zur Verfügung stellten. Die faktische Gültigkeit der „Too-big-to-fail“-These war

34 Die Fed legte eine ganze Reihe von Fazilitäten auf wie die Asset-Backed Commercial Paper Money Market Mutual Fund Liquidity Facility (AMLF), die Commercial Paper Funding Facility (CPFF), die Money Market Investor Funding Facility (MMIFF), die Primary Dealer Credit Facility (PDCF) und die Term Securities Lending Facility (TSLF). Während die Term Asset-Backed Securities Loan Facility (TALF) bis zum 31. Dezember 2009 befristet wurden, liefen andere Fazilitäten wie die Term Auction Facility (TAF) ohne eine bestimmte Fristbegrenzung weiter. 


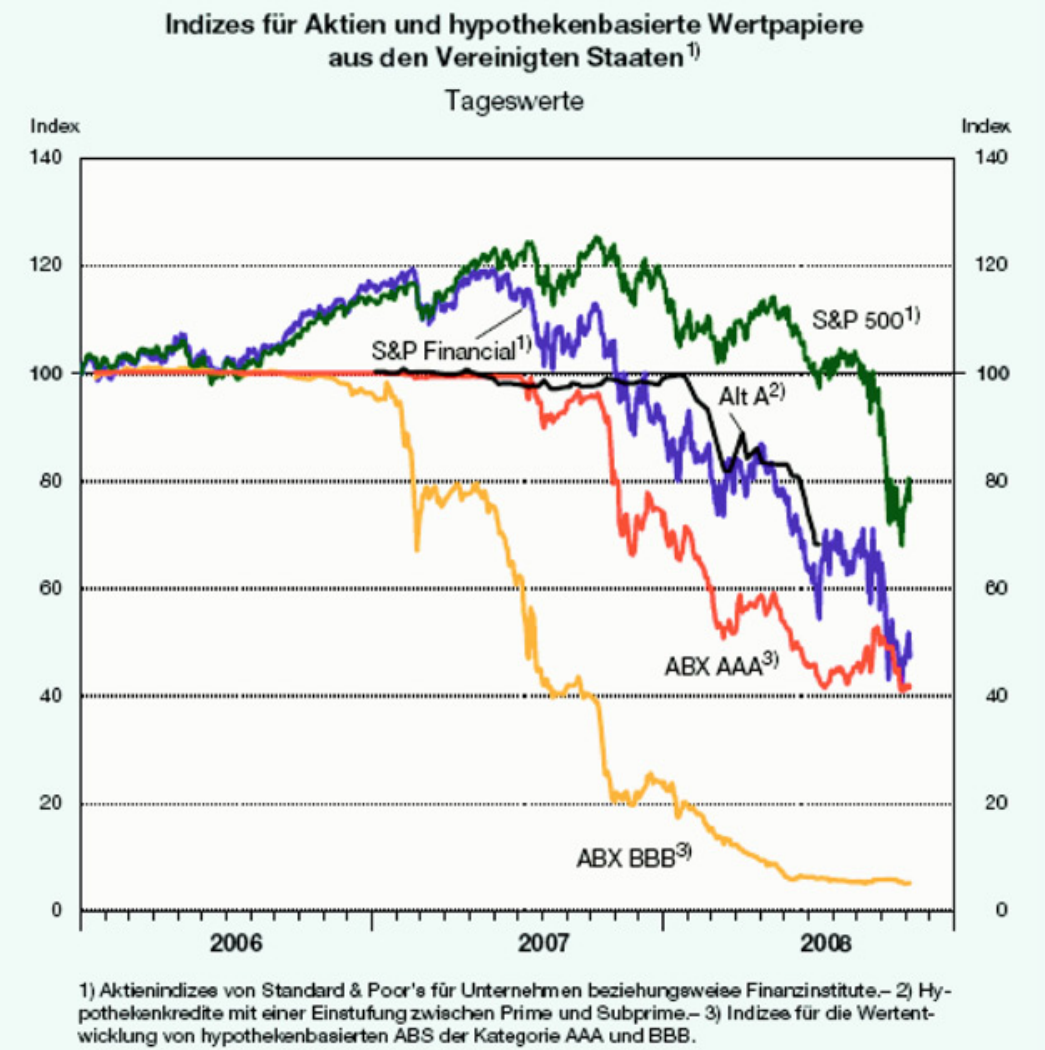

Quella: MF, Thomson Financial Datastream

- Sachverstandigenrat

Abb. 8: Verlustdynamik verschiedener Asset Klassen

mit den dramatischen Folgen ihrer Missachtung bestätigt worden. Der zusammen gebrochene Interbankenhandel musste zeitweise vollständig von den Zentralbanken durch die Eröffnung immer neuer Refinanzierungsmöglichkeiten aufgefangen werden. Dabei war es das nachvollziehbare Motiv der Verweigerung der Hilfe für Lehman gewesen, den Marktteilnehmern deutlich zu machen, dass sie sich nicht auf die "Too-big-to-fail“ Doktrin verlassen durften. Vermutlich hatte das Vertrauen auf die Hilfe des Staates bzw. der Notenbanken in Krisenzeiten dazu beigetragen, dass die Banken sehr sorglos Risiken übernommen hatten. Andererseits hatte die Unterstellung der Gültigkeit dieser Doktrin auch den Interbankenhandel gestützt, weil nicht mit jeder Transaktion eine sorgfältige Bonitätsprüfung oder Stellung von Sicherheiten verbunden sein musste. 
Das Statuieren des „Lehman-Exempels“, das auch in der akademischen Literatur durchaus gelegentlich eingefordert worden war, weil zu Recht das Gefühl bestand, dass die großen Investmentbanken auch auf Kosten der Allgemeinheit Risiken eingehen und Gewinne erwirtschaften konnten, ohne das Risiko ihrer Entscheidungen ganz selbst tragen zu müssen, führte in der Folge dazu, dass der gesamte Sektor der Investmentbanken zusammenbrach. Am 15. September 2008 übernahm die Bank of America die Investmentbank Merrill Lynch und am 21. September gaben die beiden letzten großen Häuser Goldman Sachs und Morgan Stanley ihren Status als Investmentbanken auf und stellten sich unter den Schutz des Federal Reserve Systems. Damit war das in den 1930er Jahren entstandene Trennbankensystem in den USA am Ende.

Um einen weiteren Flächenbrand zu vermeiden, griffen am 18. September die amerikanische Regierung und die Federal Reserve mit einer Kreditlinie von 85 Mrd. US\$ zur Stützung der AIG ein, der weltweit größten Versicherungsgesellschaft, die auch als wichtiger Sicherungsgeber an den Märkten für Credit Default Swaps aufgetreten war. Am 20. September beantragte das amerikanische Finanzministerium die Bewilligung zum Ankauf "toxischer" Assets der Banken. Schließlich beschloss der amerikanische Senat am 3. Oktober das Rettungspaket über $700 \mathrm{Mrd}$. \$, das aber in den Wochen danach noch vielfach diskutiert und zum Teil mit anderen Akzenten versehen wurde.

Die Reaktion auf die Krise beschränkte sich nicht auf den amerikanischen Finanzmarkt. Vielmehr reagierten viele Staaten und Notenbanken auf die Krise, indem sie aus ihrer Sicht geeignete Hilfspakete schnürten. In Deutschland wurde am 17. Oktober 2008 das Finanzmarktstabilisierungsgesetz verabschiedet, auf dessen Grundlage der Sonderfonds Finanzmarktstabilisierung SoFFin gegründet wurde, der für die deutschen Kreditinstitute Liquiditätshilfen bzw. Eigenkapitalzuschüsse oder Garantien zur Verfügung stellen sollte. Ein Teil dieser Hilfen wurde in der Zwischenzeit von den Banken abgerufen. Probleme im Management des Fonds sowie neue Schätzungen möglicher hoher Verluste und Refinanzierungsnotwendigkeiten der Banken sorgten zugleich für Diskussionen über mögliche Überarbeitungen des Rettungspakets.

\section{Die wichtigsten Treiber der internationalen Finanzkrise}

Die Banken wie die Kapitalmärkte hatten aufgrund der über viele Jahre anhaltenden Preissteigerungen am amerikanischen Immobilienmarkt die Kreditrisiken unterschätzt und sich zu völlig unzureichenden Bonitätsprüfungen verleiten lassen bzw. waren in ihrem Kreditvergabeverhalten über die Informationen aus der Bonitätsanalyse hinweggegangen. Das enorme Wachstum und der Erfolg der neuen Märkte für den Transfer von Kreditrisiken beeinträchtigte darüber hinaus die Aufmerksamkeit der Akteure an den Bank- 
märkten, seien es die Originatoren, die Risikomanager und Risikocontroller in den Banken, seien es die Wirtschaftsprüfer, die Ratingagenturen oder die Bankenaufsicht. Ein weiterer Faktor, der die Probleme der asymmetrischen Informationsverteilung verschärfen musste, lässt sich in bestimmten Übertreibungen der Verbriefungstechnik identifizieren. „The more complex the instruments are, the more opaque they are and the more money you make. So long as the underlying risk assumptions are correct, the complex product is sound. In finance, complexity has become a vice.”35 Diese Einschätzung streitet dabei den Nutzen komplexer Finanzprodukte keineswegs ab und stellt auch nicht die Möglichkeiten der Wertschaffung durch das Poolen und Tranchieren von Cashflowansprüchen an Forderungsbestände in Frage. ${ }^{36}$

Zweifelhaft war aber die Übung, die Poolzusammensetzungen und Tranchenbildungen auf die Vorgaben der Ratingagenturen abzustimmen. Zweifelhaft war auch die Bildung von CDOs auf CDOs (CDOs Squared), die den Inhabern der Titel den „Durchblick“ auf die letztlich zu erwartenden Cashflowströme noch weiter verwehrte als die übliche Einbringung der Forderungen in eine Zweckgesellschaft. In der Krise haben auch die Heterogenität der Poolforderungen sowie die mangelnde Verfügbarkeit glaubwürdiger Informationen über die zunächst als qualitativ hochwertig eingestuften Tranchen zu den Abwehrreaktionen der Anleger beigetragen. Aus einer überschaubaren Risikosituation wurde eine Unsicherheitssituation im engeren Sinne. ${ }^{37}$

Diese Wendung in der Einschätzung der Risikosituation scheint nach Caballero sogar ein ganz wesentlicher Treiber der Krise gewesen zu sein. So verstärkte der Druck der internationalen Investoren auf Zusatzrenditen zu dem zu Beginn des Jahrhunderts weltweit niedrigen Zinsniveau das mangelnde Risikobewusstsein der Marktteilnehmer. Da sich seit den späten neunziger Jahren ein internationaler Mangel an sicheren Anlagen herausgebildet hatte, konnte der Markt für Collateralised Loan Obligations mit seiner Fähigkeit, durch das Poolen und Tranchieren von Forderungen Anlagemöglichkeiten mit hohen Bonitätswerten zu konstruieren, genau diesem Anlagebedürfnis nachkommen. Die Sicherheit der Anlagen stellte sich dann allerdings bei Eintritt des Rückgangs der Immobilienpreise als Scheinsicherheit heraus. Aus dem kalkulierten geringen Risiko wurde Unsicherheit im engeren

35 Danielsson, Jon, The Myth of the Riskometer, http://www.voxeu.org, eingesehen am 24. Januar 2009, S. 1.

36 Vgl. Franke, Günter/Krahnen, Jan Pieter, The Future of Securitization, CFS Working Paper, 2008, Plantin, aaO (Fn. 14), Rudolph/Scholz, aaO (Fn. 13), Schaber, Albert, Asset Pool Quality and Tranching of CDOs. Münchener Wirtschaftswissenschaftliche Beiträge (BWL) 2009-1.

37 Caballero, Ricardo, A Global Perspective on the Great Financial Insurance Run: Causes, Consequences, and Solutions, http://www.voxeu.org, eingesehen am 24. Januar 2009, S. 1. 
Sinne mit der Folge, dass die Anleger und Banken die Übernahme neuer unsicherer Positionen vollständig verweigerten und die alten abstießen, soweit das irgendwie möglich war.

\section{Lösungs- und Reformvorschläge zur zukünftigen Krisenvermeidung}

\section{Analyserabmen der Ansatzpunkte für Veränderungen}

Die in der wissenschaftlichen Literatur, in der Praxis und in den mit der Bankenaufsicht befassten Institutionen vorgestellten Vorschläge zur langfristigen Stabilisierung des Finanzsystems sind durch verschiedene Sichtweisen geprägt. Inhaltlich hängen alle Vorschläge zusammen. Eine klare Trennung der Reformvorschläge nach dem Zuständigkeitsbereich des Bankmanagements, der Bankeigentümer, der Einzelinstitute, Bankengruppen, Ratingagenturen, Wirtschaftsprüfungsgesellschaften, der Bankenaufsicht, der Notenbanken, der Politik oder der Bankkunden ist dementsprechend in vielen Fällen nicht möglich. Vielfach sind die Lösungsvorschläge auch auf unterschiedlichen Abstraktionsebenen formuliert, wobei die Fülle konkreter Vorschläge leicht zu einer unübersichtlichen Aufzählung führt und die abstrakte Formulierung häufig relevante Ausprägungsalternativen offen lässt. ${ }^{38}$ Dennoch können einzelne wichtige Themenfelder isoliert werden, die die wichtigsten Stoßrichtungen der Reformvorschläge verdeutlichen. Im Folgenden werden insbesondere Ansatzpunkte und Vorschläge zu möglichen Maßnah-

38 So wählt z.B. Schäfer, Dorothea, Wochenbericht des DIW Berlin Nr. 51-52/2008, S. 808-817 einen vergleichsweise hohen Abstraktionsgrade, wenn sie die Minimierung des Koordinationsversagens oder die Forcierung der Subsidiarität (als die ersten zwei von insgesamt neun Tops) auf die Agenda für den Umbau der Finanzmarktarchitektur setzt. Die Vorschläge unterscheiden sich auch danach, ob sie vor oder nach dem Zusammenbruch des Bankhauses Lehman formuliert worden sind. Bis zum Zusammenbruch des Bankhauses richteten sich die Vorschläge häufig ausschließlich auf das Verhalten und die Organisation der Subprime und Verbriefungsmärkte (vgl. beispielsweise JäGER/VoIgTLändER, IW Trends 35, 2008, Heft 3, S. 1-14), während die Vorschläge nach der Lehman Insolvenz immer deutlicher den weltweiten Regulierungsrahmen und die übergeordneten Regulierungsziele thematisieren, so beispielsweise der „Geneva Report“ (Brunnermeier, Markus et al., The Fundamental Principles of Financial Regulation, Geneva Reports to the World Economy 11, 2009, http://www.voxeu.org, eingesehen am 29. Juni 2009) oder die Vorschläge des „Issing Committees“ (Issing, OtMar ET AL., New Financial Order. Recommendations by the Issing Committee, Center for Financial Studies, White Paper No. II, Febr. 2009). Vgl. zu umfassenden Bestandsaufnahmen der Ursachen, Treiber und Katalysatoren der Krise sowie zu wichtigen Vorschlägen zur Verbesserung des Finanzsystems Financial Services Authority, The Turner Review. A Regulatory Response to the Global Banking Crisis, 2009, Hellwig, Martin, Systemic Risk in the Financial Sector: An Analysis of the Subprime-Mortage Financial Crisis, Working Paper, 2008 und Sinn, Hans-Werner, Kasino-Kapitalismus. Wie es zur Finanzkrise kam, und was jetzt zu tun ist, 2009. 
men in der Bankenaufsicht und zu Veränderungen im Bereich des Risikomanagements der Banken diskutiert. Populäre Vorschläge, die die Tagesdiskussion beherrschen, werden dabei nicht aufgegriffen, wenn sie für die längerfristige Neuordnung der Finanzarchitektur, der Bankenaufsicht und des Risikomanagements der Banken wenig relevant sind. Darüber hinaus wird die Diskussion um alternative Bad-Bank-Konzepte ebenso vernachlässigt wie die weiterführenden Probleme des Einwirkens der Finanzkrise auf die Entwicklung der Realwirtschaft.

Banken sind seit vielen Jahrzehnten weltweit besonders ausgeprägten Regulierungen und aufsichtsrechtlichen Bestimmungen unterworfen, deren Notwendigkeit insbesondere mit den Problemen der asymmetrischen Informationsverteilung an den Finanzmärkten und mit ihrer Bedeutung für die Realwirtschaft begründet wird. ${ }^{39}$ Rückblickend wird man aus der Existenz und Schwere der jüngsten internationalen Finanzkrise ein schweres Marktversagen ableiten wollen, woraus prima facie abzuleiten wäre, dass der bestehende Regulierungsrahmen unzureichend war und daher in Zukunft verschärft werden muss. Allerdings ist auch nicht auszuschließen, dass die bestehenden Regulierungen selbst die Krise begünstigt oder verschärft haben, also ein Regulierungs- oder Staatsversagen zu konstatieren ist. Immerhin sind in den USA die hohen Verluste zunächst in einem staatlich stark geförderten Teilbereich des Kreditmarktes entstanden, nämlich dem amerikanischen Markt für Wohnungsbaukredite, ${ }^{40}$ und in Deutschland sind besonders große Verluste bei den öffentlichen Banken und Institutionen zu beobachten gewesen. Darüber hinaus könnte man auch davon ausgehen, dass viele bankaufsichtliche Bestimmungen im Grunde durchaus richtig angesetzt waren, dass sie aber nicht konsequent und rasch genug umgesetzt und an die wachsenden Informations- und Anreizprobleme angepasst worden waren, so dass nicht nur der Regulierungsrahmen, sondern auch die Organisation der Aufsichtsinstanzen reformbedürftig erscheinen. ${ }^{41}$ Schließlich könnte man die Effektivität insbe-

$39 \mathrm{Zu}$ den Ansatzpunkten einer staatlichen Beaufsichtigung der Banken sowie der Bewertung der Bankenaufsicht im Licht wohlfahrtsökonomischer Überlegungen vgl. Brughof, Hans-Peter/Rudolph, Bernd, Bankenaufsicht. Theorie und Praxis der Regulierung, 1996, S. $17 \mathrm{ff}$.

40 Wenn der EEAG Report, aaO (Fn. 3), die übertriebene Risikoübernahmen, eine übermäßige Verschuldung der Finanzintermediäre sowie eine extreme Undurchsichtigkeit der Höhe und Verteilung der Risiken als wesentliche Elemente der Krisenursachen herausarbeitet, dann ist darauf hinzuweisen, dass alle drei im Zentrum bankaufsichtlicher Regulierungen stehen, so dass unklar ist, warum die kritisierten Entwicklungen bankaufsichtlich nicht vor der Krise ausreichend entschärft worden sind.

41 Vgl. Hartmann-Wendels, Thomas/Hellwig, Martin/Hüther, Miachel/Jäger, ManFRED, Arbeitsweise der Bankenaufsicht vor dem Hintergrund der Finanzmarktkrise, 2009. Darüber hinaus ist darauf hinzuweisen, dass die vielfach kritisierte bankaufsichtliche Lücke in der Risikobegrenzung, dass kurzfristige Liquiditätszusagen nicht durch Eigenkapital unterlegt werden müssten, mit der Einführung von Basel II am 
sondere der US amerikanischen und der deutschten Aufsicht besonders in Zweifel ziehen, da in anderen Ländern durch das Einwirken der Aufsichtsbehörden große Verluste vermieden werden konnten. In Deutschland weist die Aufsicht dagegen darauf hin, dass ihr selbst die Hände gebunden gewesen seinen: Früher einschreiten hätte die BaFin nach dem geltenden Gesetz nicht können, verteidigte Sanio in der fünfstündigen Beratung seine Behörde. So hätte man den Kauf der irischen Depfa mit ihrem Geschäftsmodell nicht verbieten dürfen. ${ }^{“ 42}$ Zahlreiche Vorschläge zielen daher darauf ab, Informationsdefizite der Bankenaufsicht abzubauen, bestehenden Regulierungslücken für einzelne Finanzintermediäre wie Hedgefonds und Ratingagenturen zu schließen und die Möglichkeiten der Regulierungsarbitrage zu minimieren. $^{43}$

Darüber hinaus wird angeregt bzw. gefordert, das derzeitige Regime der Bankenaufsicht, das auf die Durchsetzung präventiver Sicherheitsstandards zur Sicherung der Solvenz jeder einzelnen Bank ausgelegt ist, zugunsten der Entwicklung präventiver Sicherheitsstandards zur Sicherung der Stabilität des gesamten Finanzsystems zurückzuschrauben. Die neuen Standards müssten natürlich auf die Einzelinstitute herunter gebrochen werden, aber eben „makroprudentiell“ ausgerichtet sein. Eine sehr einfache Methode für eine makroprudentiell ausgerichtete Regulierung besteht darin, die Eigenkapitalanforderungen für große Institute (too-big-to-fail) bzw. Institute, die stark mit anderen Teilen der Kreditwirtschaft stark vernetzt sind (too-connected-to fail) zu steigern. Makroprudentielle Standards müssen also nicht für alle Finanzintermediäre je nach ihrer Größe, ihrem Geschäftsbereich, ihrer Verflochtenheit mit den übrigen Intermediären oder ihrem Kundenkreis in gleicher Weise gelten. Die Bankenaufsicht müsse aber von allen Finanzintermediären über alle relevanten Sachverhalte und Transaktionen informiert werden, damit sie der Schwerpunktverlagerung der aufsichtsrechtlichen Zielsetzung und damit das neue Regime einer makroprudentiellen Regulierung wirksam vornehmen und ausfüllen kann. ${ }^{44}$

Eine weitere grundsätzliche Erkenntnis aus der Krise fließt ebenfalls in die Überlegungen zur Reform der Finanzmärkte ein, ohne dass sich daraus schon schlüssige praktische Vorschläge zur Umsetzung ergeben haben. Sehr präg-

1. Januar 2008 planmäßig geschlossen wurde, die Krise aber noch unter dem Regime von Basel I ausgebrochen war.

42 BaFin Präsident Jochen SANio vor dem HRE Untersuchungsausschuss am 29. Juli 2009. Quelle: Jahn, Joachim/Ruhkamp, Stefan, „Preiswerter ging es für den Steuerzahler nicht“, FAZ.NET vom 30. Juli 2009.

43 Vgl. beispielsweise die Übersicht über die Beschlüsse der 20 größten Industrie- und Schwellenländer auf der G20 Konferenz am 1. und 2. April 2009 in London. Vgl. hierzu die Homepage des Bundesministeriums der Finanzen (Mitteilung vom 6. April 2009).

44 Vgl. Borio, Claudio, The Macroprudential Approach to Regulation and Supervision, http://www.voxeu.org, eingesehen am 14. April 2009. 
nant findet man diese Überlegungen in einem Papier des Institute of International Finance (IIF) zusammengefasst: „Noting that successful regulation needs to operate in tandem with well-disciplined markets, the IIF emphasized that for markets to operate effectively there needs to be meaningful market discipline. This means that investors and creditors other than depositors or policy holders need to face a possibility of loss and so it needs to be made feasible for even the largest financial forms to fail. And, in this regard, the IIF noted that it should be a priority to implement the infrastructure, legal, and process reforms necessary to ensure that all firms can exit the market in an orderly fashion and without causing a systemic crisis regardless of their size, nature, or range of activities." ${ }^{\$ 5}$ In der Tat darf die Organisation der Bankmärkte oder die Identifikation von "Systembanken" nicht dazu führen, dass diese Institute eine Überlebensgarantie erhalten. Vielmehr müssen Institutionen neu entwickelt werden, die für alle Finanzmarktteilnehmer die Gefahr einer Insolvenz und eines Verlustes von eingesetztem Vermögen nicht ausschließen.

\section{Reformen der Struktur der Bankenaufsicht und des Regulierungsrabmens}

Wesentliche Vorschläge zur Verbesserung der Finanzstabilität betreffen notwendige bzw. wünschenswerte Veränderungen in der Bankenaufsicht, da es trotz des weltweit hohen Regulierungsniveaus der Finanzindustrie zu massiven Fehlentscheidungen und Schieflagen verschiedener Finanzmarktakteure und danach zu einer Krise des gesamten Finanzsystems gekommen ist. Dabei sollten die Eigenkapitalvorschriften sicherstellen, dass die von den Banken übernommenen Risiken auch in Stresssituationen durch ausreichende Eigenmittel gedeckt sind. Proberechnungen und Auswertungen der Auswirkungsstudien der Deutschen Bundesbank führten zur Feinadjustierung der Unterlegungsvorschriften für die Risiken, die Auswertung der angestellten Stresstest bis zuletzt zu keinen beunruhigenden Ergebnissen. ${ }^{46}$

Da die Krise am amerikanischen Markt für Hypothekenfinanzierungen ausgelöst wurde und erst danach hohe Verluste bei den Banken und Anlegern in

45 Institute of International Finance IIF, The Financial Industry Calls for Action to Strengthen the Global Financial System and Promote Stability in Financial Markets, Press Release, July 23, 2009.

46 Vgl. Deutsche Bundesbank, Monatsbericht, April 2004. Im November 2006 hatte die Bundesbank noch bei der Vorlage des Finanzstabilitätsberichts 2006 festgestellt, dass sich die Stabilität des deutschen Finanzsystems weiter verbessert habe und die Banken ihre Risikotragfähigkeit merklich erhöht hätten. Und auch im November 2007 geht die Bundesbank noch davon aus, dass sich die Risikotragfähigkeit der deutschen Banken auf hohem Niveau stabilisiert habe und die Banken auf einer insgesamt gestärkten Eigenkapitalbasis agierten. Vgl. Deutsche Bundesbank, Finanzstabilitätsberichte 2006 und 2007. 
anderen Ländern zu verzeichnen waren, die in die risikobehafteten Collateralized Debt Obligations investiert hatten, richten sich die Vorschläge für die amerikanischen Institute schwerpunktmäßig auf den Prozess der Kreditvergabe und des Kreditrisikotransfers, während für die deutsche Aufsicht eher das Risikomanagement im Bereich der Mittelanlage der Banken in strukturierte Produkte thematisiert wird. ${ }^{47}$ Die internationale Liquiditätskrise im Anschluss an die Verweigerung der Hilfe für Lehman Brothers hat dann darüber hinaus auch zu Überlegungen Anlass gegeben, die Rolle des „Lenders of Last Resort" für die Liquidität der Banken zu einer vergleichbaren Rolle für die Solvenz der Banken auszubauen („Lender of Last Equity Resort).

Verschiedene Vorschläge zur Weiterentwicklung bzw. zur Reform der Bankenaufsicht setzen an den nationalen und internationalen Organisationsstrukturen an, wobei Forderungen nach einer grenzüberschreitenden Bankenaufsicht im Mittelpunkt stehen. International stark vernetzte Banken erfordern hinsichtlich der Transparenz für die Bankenaufsicht, aber auch zur Vermeidung einer Regulierungsarbitrage eine Vernetzung oder sogar Zentralisierung bankaufsichtlicher Kompetenzen. Selbst in der Europäischen Union, die durch entsprechende Richtlinien über ein gemeinsames Rahmenregelwerk verfügt, lassen sich vielfältige Ausnahmevorschriften, Auslegungswahlrechte und institutionelle Abweichungen feststellen. So liegt ein wichtiges Defizit der Aufsicht nach Ansicht vieler Autoren darin, dass große Institute grenzüberschreitend tätig sind und es daher bei einer Überwachung auf nationaler Ebene leicht zu Informationsnachteilen kommt. Daher wurden grenzüberschreitende Aufsichtskollegien "Colleges of Supervisors“ bzw. "Consolidating-Supervisors“ eingerichtet, die tätig werden sollen, ohne dass nationale Rechte, Institutionen oder Regeln davon tangiert würden. ${ }^{48}$ Dafür sollen sie aber nicht nur einzelne Institute und Regionen überwachen, sondern

47 Eine kompakte Darstellung der Entwicklung und Organisation der amerikanischen Bankenaufsicht findet man in Kushmeider, Rose Marie, The U.S. Federal Financial Regulatory System: Restructuring Federal Bank Regulation, http://www.fdic.gov, eingesehen am 24. Juni 2009.

48 Überlegungen der EU-Kommission haben zur Schaffung eines Europäischen Rates für Systemrisiken (European Systemic Risk Board ESRB, bestehend aus den europäischen Notenbankpräsidenten und einem Vertreter der EU-Kommission) geführt. Vorgeschlagen wurde darüber hinaus ein Europäisches Finanzaufsichtssystem (European System of Financial Supervisors ESFS mit drei Behörden, die aus den bestehenden Ausschüssen hervorgehen, die European Banking Authority EBA, die European Insurance and Occupational Pensions Authority EIOPA sowie die European Securities Authority ESA). Vgl. Banh, Minh/Cluse, Michael, Zeitschrift für das gesamte Kreditwesen, 62 (2009), S. 629 ff, S. 630. Zur Kritik an der geplanten Aufbauorganisation einer neuen, umfassenden europäischen Finanzaufsicht vgl. Burghof, Hans-Peter, Wirtschaftdienst 89, 2009, S. 354-355. 
sollen auch horizontal ausgerichtet sein, „looking broadly across banks, securities firms, markets and geographies. “49

Bei der Umsetzung dieser Überlegungen und Vorschläge zu einem Ausbau der internationalen Bankenaufsicht gilt es allerdings zu bedenken, dass weltweit einheitliche Regelwerke auch eine nicht zu unterschätzende Gefahr mit sich bringen, wenn sie zu einem Gleichlauf der Handlungsstränge, Entscheidungen und Wertansätze der regulierten Banken und Finanzinstitutionen zwingen oder beitragen. Gibt es Risikopositionen, die aufsichtsrechtlich hinsichtlich der Eigenkapitalunterlegung - aus welchen Gründen auch immer - weniger restriktiv behandelt werden als gleich risikobehaftete Assets, so kann es zu einer Überbewertung dieser Positionen und einer Überinvestition kommen. Platzt dann die Blase, so werden die Investoren weltweit in gleicher oder ähnlicher Weise getroffen und haben mangels alternativer Bedingungen an fremden Märkten - mit anderen Regulativen - keine Möglichkeit, ihre Positionen ohne erhebliche Abschreibungen zu liquidieren. Je globaler bankaufsichtliche Regelwerke wirken, umso eher und ausgeprägter können sie in Krisenzeiten zur Illiquidität der betreffenden Positionen beitragen. Die prozyklischen Eigenschaften bankaufsichtlicher Regelwerke sind umso stärker, je umfassender alle Marktteilnehmer von ihnen erfasst werden, ein Effekt, der möglichst vermieden werden sollte.

Jenseits dieser Überlegungen, die sich auf die grenzüberschreitenden Geschäfte und die Aktivitäten der Nichtbankenintermediäre und somit auf unterschiedliche Regulierungsansprüche beziehen, sind in Deutschland Vorschläge zur Reorganisation der Kompetenzen in der Bankenaufsicht gemacht worden, die sich zwischen der Bundesanstalt für Finanzdienstleistungsaufsicht BaFin und der Deutschen Bundesbank herausgebildet und in einigen Fällen zu Doppelbelastungen und Ineffizienzen geführt haben. Dabei ist insbesondere die Nähe der Deutschen Bundesbank zu den einzelnen Instituten positiv hervorgehoben worden, woraus dann die auch international vertretene Anregung unterstützt wurde, die Rolle der Zentralbanken bei der Bankenaufsicht zu stärken. Letztlich ist dabei aber in Deutschland das grundsätzliche Zusammenwirken der beiden Instanzen nicht in Frage gestellt worden, während in den USA an der Vielzahl nationaler und bundesstaatlicher Institutionen, die an der Bankenaufsicht beteiligt sind, durchaus Kritik geübt worden ist.

Neben einer Neuausrichtung der verschiedenen nationalen und internationalen Institutionen, die mit der Bankenaufsicht betraut sind, wird eine Erweiterung des Kompetenzbereichs dieser Institutionen gefordert. Diese Forderung bezieht sich nicht nur auf verschärfte Eingriffsbefugnisse in die Geschäftstätigkeit der Banken und auf die Informationsmöglichkeiten, sondern

49 Dudley, William C., Lessons Learned from the Financial Crisis, Remarks at the 8th Annual BIS Conference, 2009. 
es wird darüber hinaus ein weltweit harmonisiertes bankenspezifisches Insolvenzregime mit frühzeitigen Eingriffsbefugnissen der Behörden gefordert („prompt corrective action“). ${ }^{50}$

\section{Verbesserungen der bankaufsichtlichen Regelwerke}

Bei der Frage der Verbesserung der inhaltlichen Ausrichtung der Aufsicht spielt die Reform bankaufsichtlicher Regelwerke und Instrumente eine wichtige Rolle. Hier sind insbesondere Forderungen nach einer Verfeinerung bzw. Ergänzung oder sogar einem Umbau der Risikomesssysteme und der Risikokontrolle sowie des Einbezugs der Liquiditäts- und Fristentransformationsrisiken in die quantitative Bankenaufsicht zu nennen. Die vergangenen Jahre waren im Zuge der Anpassung an die vielfältigen Regelwerke, die vom Basler Ausschuss für Bankenaufsicht entwickelt und vorgegeben wurden, durch eine immer weiter gehende quantitative Ausrichtung vieler Instrumente gekennzeichnet, z.B. bei der Einbeziehung und quantitativen Erfassung operationaler Risiken oder dem Ausbau der Value-at-Risk Risikomessverfahren, der Simulationsrechnungen und Szenarioanalysen sowie vieler anderer statistisch anspruchsvoller Instrumente. ${ }^{51}$ Die Konzeption von Basel II sollte die starren Instrumente des Baseler Akkords von 1988 überwinden und die bankaufsichtlichen Anforderungen und die von den Kreditinstituten selbst verwendeten Risikomess- und Risikomanagementverfahren so weit wie möglich synchronisieren. Dieses Ziel wurde mit der Konzeption von Basel II und in den darauf aufbauenden EU Richtlinien sowie in ihren Umsetzungen in die Solvabilitätsverordnung und die MaRisk auch weitgehend erreicht und bewirkte, dass die Banken je nach den für sie zweckmäßigsten Anforderungen und dem anerkannten Ausbaugrad ihrer Risikomanagementsysteme zwischen

50 Vgl. Dewatripont, Mathias/Rochet, Jean-Charles, in: M. Dewatripont et al. (Hrsg.), Macroeconomic Stability and Financial Regulation: Key Issues for the G20, CEPR 2009, S. 149-164.

51 Die Regeln zur internationalen Konvergenz der Kapitalmessung und der Eigenkapitalanforderungen (Basel II) wurden im Juni 2004 vom Baseler Ausschuss für Bankenaufsicht beschlossen und in zwei EU-Richtlinien in europäisches Recht übertragen (im Juni 2006 insbesondere durch die Bankenrichtlinie (2006/48/EG) und die Kapitaladäquanzrichtlinie (2006/49/EG)). Die Übernahme der europäischen Vorgaben in deutsches Recht erfolgte durch die Solvabilitätsverordnung (SolvV), durch die Groß- und Millionenkreditverordnung (GroMiKV) und durch die Liquiditätsverordnung (LiqV). Mit der Solvabilitätsverordnung wurden im Kern die Säulen 1 und 3 von Basel II, mit den Mindestanforderungen an das Risikomanagement (MaRisk) der Bundesanstalt für Finanzdienstleistungsaufsicht BaFin die Säule 2 von Basel II in das deutsche Aufsichtsrecht eingefügt. Ein neuer Vorschlag zur Änderung der Eigenkapitalvorschriften ist im Juli 2009 von der Kommission angenommen worden und betrifft die Kapitalanforderungen für das Handelsbuch und für Wiederverbriefungen, die Offenlegung von Verbriefungsrisiken und die Vergütungspolitik. 
alternativen Risikomesssystemen wählen konnten. Die aufsichtlichen Kapitalanforderungen orientieren sich mit Basel II an den gemessenen Risiken, so dass im Konjunkturaufschwung mit abnehmenden Risiken aufsichtliches Eigenkapital freigesetzt wurde, was zusätzliche Investitionen in risikobehaftete Anlagen zur „Auslastung“ des „teuren“ Eigenkapitals induzierte. Die Vorschriften von Basel II traten zwar erst zum Jahreswechsel 2007/2008 in Kraft, prägten aber in wesentlichen Teilen (offenbar nicht bei der Eigenkapitalunterlegung der Liquiditätsfazilitäten) das Verhalten der Kreditinstitute, weil diese sich auf die neuen Regelwerke und den neuen Umgang mit ihren Kunden längerfristig einstellen mussten. Jedenfalls waren die Jahre nach 2004 für viele deutsche Kreditinstitute bereits durch die Umstellungsarbeiten im Zuge der Anpassung an das Regelwerk von Basel II geprägt.

Die zweite Säule von Basel II, die das aufsichtsrechtliche Überprüfungsverfahren (Supervisory Review Process) vorsieht, wird durch den Internal Capital Adequacy Assessment Process ICAAP ausgefüllt, der in den Rahmen der MaRisk eingebettet ist und eine angemessene Identifikation, Messung, Aggregation und Überwachung aller wesentlichen Risiken der Bank (Risikoprofil) fordert sowie die Adäquanz des hierfür gehaltenen Kapitals sicherstellen muss (Risikotragfähigkeitsanalyse). Im Rahmen der Risikotragfähigkeitsanalyse kommt dabei der Durchführung von Stress Tests eine besondere Bedeutung zu. Stress Tests sollen nämlich zeigen, ob die bestehenden regulatorischen Kapitalanforderungen auch im Fall von Krisenereignissen wie Zins- oder Wechselkursschocks oder im Fall eines Börsencrashs ausreichend bemessen sind, wobei in der Praxis risikoartenspezifische und übergreifende Stress Tests sowie Tests für schwer quantifizierbare Risiken und Tests für Risiken unterschieden werden, die nur der Gesamtbank zugerechnet werden können. ${ }^{52}$

Der Baseler Ausschusses hat im Juli 2009 eine Überarbeitung des Basel II Pakets verabschiedet, das nicht nur strengere Anforderungen an die Parameterausgestaltung der internen Modelle für die Bemessung von Marktsrisiken vorsieht, sondern auch die wöchentliche Bestimmung eines Stressed Value-atRisk, der dem bisherigen aufsichtlichen Mindestkapital hinzuzurechnen ist. „Die Forderung nach einem Kapitalzuschlag für den Stressed VaR unterstreicht den Stellenwert von Stresstests in den neuen Aufsichtsnormen, welcher sich auch in den erweiterten Anforderungen der MaRisk widerspiegelt. ${ }^{* 53}$

52 Vgl. Annetzberger, Christian/Gann, Philipp, in: Klaus Schäfer et al. (Hrsg.), Risikomanagement und kapitalmarktorientierte Finanzierung, 2009, S. 473-494.

53 Banh/Cluse, aaO (Fn. 48), S. 633. Der Baseler Ausschuss geht davon aus, dass die zusätzlichen Stressed Value-at-Risk Kapitalanforderungen die prozyklischen Wirkungen der Mindesteigenkapitalvorschriften vermindern können. Vgl. Basel Committee on Banking Supervision, Revisions to the Basel II Market Risk Framework, Bank for International Settlements, July 2009, S. 1. Vgl. auch Basel Committee on Banking Su- 
Fraglich ist bei dem bislang bekannten Konzept allerdings, ob die ,Incremental Risk Charge' sinnvoll angesetzt werden kann, wenn für die verschiedenen Value-at-Risk-Zahlen unterschiedliche Halteperioden und unterschiedliche Konfidenzniveaus vorgegeben sind. ${ }^{54}$

Jenseits der bekannten Kritik am Value-at-Risk Konzept ist darauf hinzuweisen, dass die Verquickung von Risikokennzahlen mit anderen Kennzahlen zu nicht interpretierbaren Größen - wie z. B. bei den RAROC Kennzahlen die unglückliche Entwicklung des Risikomanagements begünstigen und der Risikokontrollapparat immer weiter ausgedehnt und verfeinert wird. Gleichzeitig wächst aber die Intransparenz, die durch eine mangelnde Interpretierbarkeit der Kennzahlen gesteigert wird, und die Ergebnisse der Risikomessung werden gegenüber einer kritischen Beleuchtung abgeschottet. Schließlich ist auf die Gefahr hinzuweisen, dass die besonders anspruchsvollen und überwiegend technischen Risikomess- und Risikosteuerungsinstrumente das Bankmanagement und die Bankmitarbeiter gegenüber den Ergebnissen robuster Checks immunisieren können. So wurde in den Jahren vor der Finanzkrise die Risikomessung und Risikosteuerung weitgehend den „Technikern“ des Risikomanagements überlassen mit der Folge, dass auch das Gespür für Inkonsistenzen im Ertrags-Risiko-Verhältnis eingegangener Positionen in den Vorständen der Kreditinstitute verdrängt wurde. Darüber hinaus wurden warnende Stimmen in den Bank selbst nicht mehr ausreichend gehört, weil sie sich nicht auf dem neu eingeführten technisch hohen Niveau artikulieren konnten und daher nicht ernst genommen wurden. ${ }^{55}$

Dementsprechend gibt es Vorschläge, die aufsichtlichen Kapitalanforderungen um Restriktionen zu ergänzen, die auf leicht messbare, also transparente Größen ausgerichtet sind und beispielsweise einen maximalen Verschuldungsgrad oder eine untere Schranke für den Anteil des Eigenkapitals an der Bilanzsumme ergänzend zu den Basel II-Regeln vorschreiben. ${ }^{56}$ Die Ziel-

pervision, Enhancements to the Basel II Framework, Bank for International Settlements, July 2009.

54 Vgl. zur Kritik an der (bislang noch nicht ganz ausgearbeiteten) Regulierung CampbelL, Alexander, Deutsches Risk, 2009, S. 17 ff, S. 21.

55 Zuberbühler, Daniel, Finanzkrise und Bankenaufsicht, Handout zu einem Vortrag bei Bratschi Wiederkehr \& Buob, Zürich, 15. Mai 2008 macht die Angabe, dass allein im bankeigenen Apparat der Risikokontrolle der UBS über 3.400 Personen beschäftigt waren.

56 Vgl. die Übersicht und Bewertung bei Schierenbeck, Henner/Pohl, Michael, Der Schweizer Treuhänder 2009, Heft 1-2, S. 8-14. Die Kritik an der Leverage-Ratio betont die mangelnde theoretische Verknüpfung der Zahlen. Dabei könnte man allerdings das Volumen der Assets als Approximation jener Risiken interpretieren, die sich den üblichen quantitativen Risikomesssystemen entziehen. Der Baseler Bankenausschuss fordert eine Begrenzung der Bilanzsumme als Vielfaches des Eigenkapitals, also eine Leverage-Ratio, hat sich aber bis Ende 2009 noch nicht auf eine Norm festgelegt. 
richtung ist dabei klar, dass die Regulierung auf finanzielle Kennzahlen abstellen soll, die möglichst transparent sind und innerhalb und außerhalb der Banken von den Marktteilnehmern beobachtet werden können. Damit könnte auch im Sinne der zweiten Säule von Basel II die Verbindung der internen Kontrolle zum bankaufsichtlichen Überprüfungsverfahren gestärkt werden, wenn die Aufsicht plötzliche Ausreißer der Leverage Ratio beim Bankmanagement zur Sprache bringt. Damit solche Kontrollvorgänge wirksam werden, bedarf es einer ausreichenden Qualität und entsprechender Anreize der Aufsichts- und Verwaltungsräte, der Wirtschaftprüfer und der Bankmitarbeiter in der Bankenaufsicht. Ganz offensichtlich gibt es hier vielfältige Ansatzpunkte für eine Umorientierung und für Verbesserungen im Einzelnen.

Kritisiert worden ist auch, dass sich die technisch ausgefeilten Risikomesssysteme stets nur auf die mögliche Insolvenzsituation einzelner Banken beziehen und keine Abschätzung des Beitrags der Bank zu einer möglichen Systemkrise des Bankensektors erlauben. Wie die internationale Finanzkrise aber deutlich gemacht hat, sollten bankaufsichtliche Regelwerke gerade auf eine solche Situation zugeschnitten sein. „Emphasizing counterparty risk as a factor in the crisis also suggests that minimum capital requirements should be set not on the basis of the riskiness of a bank's individual assets and liabilities but with the potential of its difficulties for the rest of the financial system in mind. Capital requirements should reflect implications for systemic stability, not just implications for the subject institution taken in isolation." ${ }^{57}$

Eine häufig vorgebrachte Anregung zur Reform der Finanzmarktaufsicht betrifft die Vermeidung von Ausnahmebereichen der Regulierung insbesondere in den Fällen, in denen diese zum Anlass einer Regulierungsarbitrage genommen werden können. So gelten die Liquiditätszusagen der Sponsoren an die oben beschriebenen Conduits als typische Vehikel zur Durchführung einer Regulierungsarbitrage, da Liquiditätszusagen bis zum Inkrafttreten von Basel II im Januar 2008 keinen regulativen Eigenkapitalanforderungen unterworfenen waren. Die Unterlegung eines Risikos mit Eigenkapital sollte nicht davon abhängig sein, ob ein Risiko innerhalb oder außerhalb eines Konzerns übernommen wird oder in welcher Subeinheit es durchgeführt wird (same risk, same rule). Zum Phänomen der Regulierungsarbitrage kann man auch die 2004 erlassene, in der Zwischenzeit aber nicht mehr relevante Ausnahme für die amerikanischen Investmentbanken rechnen, die Leverage-Ratios zwischen den Risikoaktiva und dem Eigenkapital von bis zu 1 zu 40 ermöglicht hatte. ${ }^{58}$ Schließlich darf auch die Eigenkapitalunterlegung nicht davon abhängig sein, ob ein Risiko im Anlagebuch einer Bank oder im

Das Institute of International Finance, aaO (Fn. 45), hält dagegen wie die Kreditinstitute selbst eine solche risikoinsensitive Restriktion für kontraproduktiv.

57 Eichengreen, Barry, Financial Stability Review 11 (2008), S. $19 \mathrm{ff}$.

58 Vgl. Paul, Stephan, Institut für Kredit- und Finanzwirtschaft, wissen \& handeln, 2008, S. 14. 
Wertpapierbestand verbucht worden ist. Bei diesen prinzipiellen Anregungen gilt es allerdings zu bedenken, dass der Grundsatz, dass Regulierungsarbitrage in jedem Fall verhindert werden sollte, im konkreten Fall nicht leicht umsetzbar ist.

Die Vorschriften des Baseler Ausschusses sind nicht nur wegen ihrer hohen Komplexität, sondern auch dahingehend kritisiert worden, dass sie für das gesamte Bankensystem prozyklische Wirkungen entfalten können. Bei einem in den Risikomesssystemen festgestellten Rückgang der Risiken wegen eines guten konjunkturellen Umfeldes übernehmen die Kreditinstitute zusätzliche Risiken und fordern dafür gegebenenfalls nur geringe Risikoprämien. Wenn zusätzliche Mittel zur Verfügung stehen, wirkt dies stimulierend auf die Preise an den Asset-Märkten wie auf die Marktteilnehmer, die ihre Ertragssituation verbessern können, was wiederum das Risikoprofil der Finanzintermediäre begünstigt. Darüber hinaus besteht in einer solchen Situation für die Banken die Neigung, durch Aktienrückkäufe das Eigenkapital zu verringern, um den Leverageeffekt auszunutzen und die Eigenkapitalrendite zu steigern. Kommt es dann aber aufgrund eines exogenen Schocks oder eines konjunkturellen Umschwungs zu einem Anstieg der gemessenen Risiken, so ergibt sich bei allen Kreditinstituten wieder ein gleichgerichtetes Verhalten, nun aber in Richtung einer Abwärtsspirale. Alle Institute stehen nun mehr oder weniger zeitgleich in einem Zwang zum Abbau von Risikopositionen und zur Aufstockung des Eigenkapitals. Das gemeinsame „Deleveraging“ der Banken führt seinerseits zu Anspannungen an den Märkten, einem weiteren Preisverfall der unter Druck geratenen Assets und zu einer Verschlechterung der Bedingungen für eine Eigenkapitalbeschaffung. Damit wird auch die Übernahme neuer Risiken behindert oder erschwert mit den bekannten ungünstigen Effekten für die Realwirtschaft. ${ }^{59}$

Hellwig ergänzt die Kritik an den prozyklischen Wirkungen der derzeitigen Eigenkapitalregulierung um das Argument der Widersprüchlichkeit der funktionalen Bedeutung des Bankeigenkapitals in der Bankregulierung. „Unfortunately, there is a paradox involved: Equity capital that a bank needs to meet regulatory requirements is not available as a buffer against losses, which would be the usual function of 'unregulated' equity capital. Through this paradox, capital regulation itself has also contributed to the crisis." ${ }^{60}$ Von Goodhart stammt eine kleine Geschichte, die erstens die gelegentlich unvereinbare Doppelfunktion des Bankeigenkapitals als Puffer und Trigger her-

59 Vgl. Adrian, Tobias/Shin, Hyun Song, Banque de France (ed.): Financial Stability Review 11 (2008), S. 1-7 mit einer instruktive Beispielrechnung zur Verstärkerwirkung finanzieller Restriktionen. Vgl. auch Sachverständigenrat zur Begutachtung der gesamtwirtschaftlichen Entwicklung, 2008, S. 128.

60 Hellwig, Martin, Preface to: Hans-Werner Sinn, Risk-Taking, Limited Liability and the Banking Crisis, Selected Reprints, ifo Institute for Economic Research 2009, S. 1-2, S. 2. 
ausstellt und zweitens deutlich macht, dass eine Regulierung, die formale Anforderungen über die funktionalen Erfordernisse setzt, kontraproduktiv wirken kann: „The most salient metaphor and fable in prudential regulation is of the weary traveller who arrives at the railway station late at night, and, to his delight, sees a taxi there who could take him to his distant destination. He hails the taxi, but the taxi driver replies that he cannot take him, since local bylaws require that there must always be one taxi standing ready at the station. Required liquidity is not true, usable liquidity. Nor might I add, is required minimum capital fully usable capital from the point of view of a bank. ${ }^{61}$

Die Risikobegrenzungsfunktion und die Pufferfunktion des Eigenkapitals können nach also nicht zugleich erfüllt werden, spielen aber beide in bankaufsichtlichen Regelwerken eine herausragende Rolle. Weil der Risikopuffer bei der Erfüllung der Risikobegrenzungsfunktion im Falle des Bedarfs nicht in Anspruch genommen werden darf, zwingt die Mindesteigenkapitalregel in der Krise zu einer Anpassung, die die Prozyklik der Märkte verstärkt. Die Vorschläge für ein „dynamic provisioning“ zum Aufbau eines antizyklischen Puffers bzw. das „buffering“ sowie eine antizyklische Anpassung der Risikogewichte zielen in diese Richtung. ${ }^{62}$

Zur Vermeidung der Gefahren eines Credit Crunch im Konjunkturrückgang durch die Eigenkapitalregulierung werden in verschiedenen Stellungsnahmen höhere Eigenkapitalpuffer in konjunkturell günstigen Situationen gefordert, die dann im Abschwung ohne größeren Anpassungszwang abgebaut werden könnten sowie weniger risikosensitive und damit weniger zyklisch wirkende Eigenkapitalvorschriften. Vorstellbar erscheinen auch gewisse Anbindungen des Mindesteigenkapitals der Kreditinstitute an Abweichungen des aktuellen Bilanzwertes der Assets von ihrem langfristigen Durchschnittswert, der beispielsweise durch eine offizielle Stelle benannt werden könnte und dem damit der Charakter eines Fundamentalwertes zukäme. Als besonderes Problem hat sich in der Finanzkrise nämlich die Anbindung des aufsichtlichen Mindesteigenkapitals der Banken an die Bilanzansätze nach dem Fair Value Prinzip herausgestellt, denen ihrerseits schon gewisse prozyklische Wirkungen zugeschrieben werden.

Eine Studie der Universität Bochum und Oppenheim Research vom September 2008 bescheinigt dem Fair Value Accounting zwar, dass es nicht als Ursache der internationalen Finanzkrise ausgemacht werden kann, dass aber das Tageswertprinzip die Verschärfung der Krise zum Flächenbrand begünstigt hat. Insbesondere wird festgestellt, dass das IFSR Fair Value Accounting bei Kreditinstituten und Versicherungen prozyklische Ergebnisef-

61 Goodhart, Charles, Banque de France: Financial Stability Review No. 11, Febr. 2008, S. $39 \mathrm{ff}$, S. 41.

62 Vgl. das Statement des stellvertretenden Hauptgeschäftsführers des Bundesverbandes deutscher Banken Hans-Joachim Massenberg vom 15. Juli 2009. 
fekte und steigende Ergebnisvolatilitäten bewirkt. Da bei den Kreditinstituten und Versicherungen an das bilanzielle Eigenkapital auch noch Rechts- und Handlungsfolgen der Aufsichtsbehörden gebunden sind, werden Finanzkrisen und realwirtschaftliche Schocks durch das Fair Value Accounting sogar zwingend aneinander gebunden, was die prozyklischen Effekte des Fair Value Ansatzes noch verstärkt. ${ }^{63}$

Im Zuge der Reaktionen auf die internationale Finanzkrise sind in der Zwischenzeit technische Anpassungen der Ermittlung von Fair Values bei illiquiden Assets vorgenommen worden. Weitergehend kann man sich vorstellen, dass regulierende Vorschriften insgesamt von den aktuellen Tageswerten hinreichend entkoppelt werden, was in Verbindung mit den Forderungen nach einfach messbaren Systemen wie Verschuldungsgraden und Eigenkapitalbilanzsummenrelationen ebenfalls für eine Vereinfachung der aufsichtlichen Risikomesssysteme spricht. ${ }^{64}$

Die vehement diskutierte Frage der Vermeidung zusätzlicher prozyklischer Effekte durch die Bankenaufsicht wird durch Forderungen nach einer Stärkung makroprudentieller Regulierungen abgerundet. ${ }^{65}$ Diese Forderungen werden beispielsweise in dem Vorschlag konkretisiert, die regulativen Eigenkapitalanforderungen zu erhöhen, wenn die Kreditmärkte oder bestimmte Assetmärkte ein überdurchschnittliches Wachstum aufweisen oder über einen ungewöhnlich hohen Fremdkapitalhebel (Leverage) finanziert wird. Die Konkretisierung einer solchen Erhöhung der Eigenkapitalunterlegung ist aber nur dann sinnvoll umsetzbar, wenn bei den Bankaufsichtsbehörden entsprechende Informationen vorliegen, was die Issing-Gruppe zum Vorschlag der

63 Vgl. Sal. Oppenheim Pressemitteilung vom 23. September 2008.

64 Vgl. zur aktuellen Diskussion Baetge, Jörg/Brembt, Tobias/Brüggemann, Peter, Die Wirtschaftsprüfung (2008), S. 1001-1010 sowie Lüdenbach, Norbert/Freiberg, Jens, Praxis der internationalen Rechungslegung 4 (2008), S. 370-375.

65 Nach Persaud, Avinash, The Rise and Apparent Fall of Macro-prudential Regulation, Manuskript unter: http://www.voxeu.org/index.php ?q=node/3694, 2009, S. 1-2, ist der Begriff makroprudentiell vermutlich erstmals in den späten achtziger Jahren aufgetaucht und wurde von Makroökonomen ebenso wie in Veröffentlichungen der Bank für Internationalen Zahlungsausgleich BIZ konkretisiert und popularisiert (vgl. BoRIo, Claudio, aaO (Fn. 44). Dabei basiert der Begriff auf der Erkenntnis, dass das individuell umsichtige Verhalten der Finanzmarktteilnehmer im kollektiven Zusammenspiel erhebliche systemische Probleme generieren kann. Eine makroprudentiell ausgerichtete Regulierung sollte also zu einem Entscheidungsverhalten der Banken beitragen, das möglichst immer dann von dem einzelwirtschaftlich optimalen oder mikroprudentiell eingeforderten Verhalten abweicht, wenn das aus mikroprudentieller Sicht richtige, aber gleichgerichtete Verhalten aller Finanzmarktteilnehmer zu einer Systemkrise beitragen kann. Das einzelwirtschaftlich richtige Verhalten kann nämlich, wenn es von vielen Marktteilnehmern verfolgt wird, zu einem Abbau von Diversifikationsmöglichkeiten bzw. einem Aufbau systemischer Risiken führen. 
Erstellung einer globalen „Risk Map“ geführt hat. ${ }^{66}$ Diese „Risk Map“ soll die globale Verteilung der Risikoexposures erfassen, abbilden und in ein Frühwarnsystem einbringen, das den Aufsichtsbehörden entsprechende Reaktionen nahe legt. ${ }^{67}$ Makroprudentielle Regeln sollen zugleich auch die prozyklischen Wirkungen bankaufsichtlicher Regulierungen vermindern.

\section{Abbau von Friktionen im Prozess des Kreditrisikotransfers}

Lösungsvorschläge zur Krisenbewältigung und Krisenprophylaxe dürfen sich nicht auf Anpassungen oder den Ausbau regulativer Maßnahmen beschränken, sondern müssen auch bei den Kreditinstituten selbst ansetzen, die zumindest aus der ex post Perspektive ganz offensichtlich in ihrer Gesamtheit erhebliche Defizite im Risikomanagement aufzuweisen hatten. Der Verdacht liegt nahe, dass die Risiken aus den Liquiditätszusagen unterhalb der Messschwellen des Managements und der Regulierungsschwellen der Bankaufsicht lagen, weil es sonst nicht zu einem solchen Missverhältnis des risikobehafteten zum gesamten Geschäftsumfangs hätte kommen können.

Werden nun allerdings spezifische Vorschläge für das Risikomanagement der Kreditwirtschaft formuliert, so gilt es dabei zu beachten, dass die Geschäftsmodelle der Banken weltweit sehr unterschiedlich sind. Wenn beispielsweise vorgeschlagen wird, die Friktionen der auf viele beteiligte Akteure aufgelösten Wertschöpfungskette im Risikotransferprozess abzubauen, so trifft dieser Hinweis überwiegend den amerikanischen Finanzmarkt, ist aber für den deutschen Markt weitgehend gegenstandslos, weil hier beispielsweise die BaFin darauf dringt, dass das Outsourcing bestimmter Teilleistungen unter der strikten Verantwortung der auslagernden Stellen erfolgt. Auch sind die besonders sorgfältig konstruierten True Sale Transaktionen am deutschen Markt mit den in den Jahren ab 2002 getätigten Transaktionen zum Kreditrisikotransfer am amerikanischen Markt für Wohnimmobilienkredite in keiner Weise vergleichbar. ${ }^{68}$

In den USA hat der überzogene Ausbau des „Originate and Distribute Modells" dazu beigetragen, dass vielfältige Friktionen zwischen den Kreditnehmern, den Originatoren und Arrangeuren der Kreditpools sowie zwischen

66 Borio, Claudio, aaO (Fn. 44), fordert darüber hinaus, dass aus makroprudentieller Sicht großen oder stark verflochtenen systemrelevante Banken strengere Standards auferlegt werden sollten als kleineren Instituten.

67 Issing ET AL., aaO (Fn. 38), S. 15 Fn. 19 wollen das endgültige Format der systemischen Risikoerfassung zukünftigen Detailarbeiten überlassen, die einsetzen müssen, wenn die Zweckmäßigkeit der Risk Map erst einmal grundsätzlich bejaht wird. Auch der Vorschlag des Aufbaus eines globalen Kreditregisters wie eines globalen Anleiheregisters zielt auf vergleichbare Transparenzziele wie die Risk Map.

68 Vgl. Bechtold, Hartmut, Zeitschrift für das gesamte Kreditwesen 62 (2009), S. 42-43. 
den Arrangeuren der Pools und den Asset Managern bzw. den Investoren aufgetreten sind. Die hinter diesen Friktionen stehenden Probleme der asymmetrischen Informationsverteilung und die damit zusammenhängenden Risiken des Moral Hazard, der Adverse Selection und der Collusion sind dort weitgehend verdrängt worden. ${ }^{69}$ Die diesbezüglichen Lösungsvorschläge betreffen dementsprechend die Sorgfaltspflichten auf den einzelnen Stufen des Kreditvergabeprozesses sowie die Prozesse des Risikotransfers am amerikanischen Markt. ${ }^{70}$ Darüber hinaus wird gefordert, dass Aufsichtsbehörden eine Handhabe gegen Intermediäre haben müssen, die eine Umorganisation ihrer Geschäftsprozesse dahingehend vornehmen, dass die Informationsbereitstellung für die Aufsicht erschwert oder die Kontrolle eingeschränkt wird.

$\mathrm{Zu}$ den Faktoren, die die Probleme der asymmetrischen Informationsverteilung im Bankensektor und danach an den Finanzmärkten verschärft haben, gehören, wie oben bereits ausführlich dargelegt, die immer weitergehende Aufspaltung der Wertschöpfungskette der Kreditvergabe und Refinanzierung, die insbesondere bei der Finanzierung amerikanischer Wohnimmobilien beobachtet werden konnte. Dabei wurde das mit einer Kreditvergabe verbundene Bonitätsrisiko mit Hilfe verschiedener Instrumente des Kreditrisikotransfers auf andere Marktteilnehmer übertragen. Es muss dabei davon ausgegangen werden, dass die Mehrzahl dieser Marktteilnehmer weder das von ihnen übernommene Risiko vollständig erkannt haben noch fundierte Vorstellungen darüber besaßen, welche Risiken andere Marktteilnehmer über ihre verschiedenen Engagements an diesen Märkten übernommen hatten.

Gefordert wird insbesondere die Umgestaltung der Bonusverträge für die verschiedenen Transaktionspartner hinsichtlich ihrer Nachhaltigkeit und der Teilnahme an einem in den Folgeperioden möglicherweise auftretenden Verlust. Eine rein umsatz- oder ergebnisorientierte Vergütung führt, wie die Subprime Krise deutlich gezeigt hat, zum Aufbau großer Risiken, wenn die beteiligten Akteure, seien es die Finanzintermediäre als Institutionen, seien es die Portfoliomanager, nur in den Genuss positiver Ergebnisverbesserungen, nicht aber in die missliche Situation einer möglichen Verlustteilnahme in den Folgeperioden gebracht werden. Darüber hinaus sollte auch im Kreditvermittlungsgeschäft, das für den amerikanischen Bankenmarkt nicht ungewöhnlich ist, eine ausreichende Qualitätskontrolle der Beteiligten, der Prozesse sowie der dort abgeschlossenen Verträge gewährleistet werden.

69 Vgl. den detaillierten Überblick bei Ashcraft, Adam B./Schuermann, Til, Understanding the Securitization of Subprime Mortgage Credit, Federal Reserve Bank of New York, Staff Report No. 318, 2008.

70 Die Qualität der in Deutschland verbrieften Forderungen wird demgegenüber als hoch eingeschätzt, da sich auf das „Originate-and-Distribute“-Modell nicht so stark durchgesetzt hat wie in den USA. Vgl. Jurgeit, Ludwig/Müller, Dirk/Polder, Daniel, Risiko-Manager 2009, Heft 6, S. 8. Der Beitrag beleuchtet auch die Empfehlungen des Joint Forums der BIZ zum Umgang mit Verbriefungen. 
In eine ähnliche Richtung weisen auch alle Vorschläge, auf die hier nicht im Einzelnen eingegangen werden soll, die sich mit den Messsystemen und dem Verhalten der Ratingagenturen in der Krise beschäftigen. Insbesondere ist in der Zwischenzeit die Forderung nach einem Verbot der gleichzeitigen Bewertung im Verbriefungsgeschäft einerseits sowie der Beratung bei der Strukturierung der Produkte andererseits Allgemeingut geworden, ohne dass dabei ganz klar ist, ob dadurch alle Interessenkollisionen vermieden werden können. Die Ratingagenturen werden vielfach als wesentliche Treiber der Krise gebrandmarkt, wobei allerdings nicht erwiesen ist, dass die erteilten Ratings im Hinblick auf die von ihnen kommunizierten Maßstäbe grundsätzlich falsch waren. Immerhin haben sich die Ausfallwahrscheinlichkeiten vieler Papiere in der Krise danach kaum dramatisch verschlechtert. Die Vergabe eines bestimmten Ratings stellt nämlich auf die Ausfallwahrscheinlichkeit des Assetpools ab und nicht auf Marktpreisänderungen oder Veränderungen der Liquidität der Märkte. Der dramatische Verfall der Preise für CDOs und anderer Anleihearten war insbesondere Ausdruck einer Liquiditätskrise und weniger die Reaktion auf die sich verschlechternden Cashflow Projektionen der Pools. ${ }^{71}$ Zur Liquiditätskrise haben die Ratingagenturen allerdings dadurch beigetragen, dass sie zu einigen Terminen eine massenhafte Abwertung von Asset Backed Securities vorgenommen und veröffentlicht hatten, wodurch bei zahlreichen Investoren ein Verkaufszwang entstand, der den Preisverfall der strukturierten Produkte beschleunigen musste.

Bei den Forderungen zur stärkeren Kontrolle der Ratingagenturen muss bedacht werden, dass nicht auszuschließen ist, dass insbesondere die staatliche Aufwertung der Agenturen diesen eine weitergehende Bedeutung hat zukommen lassen, die dann im Zuge des gemeinsamen Beratungs- und Bewertungsansatzes offenbar missbraucht worden ist. Die Aufwertung lässt sich mit

71 Vgl. Mason, Joseph R./Rosner, Joshua, Where Did the Risk Go? How Misapplied Bond Ratings Cause Mortgage Backed Securities and Collateralized Debt Obligation Market Disruptions, Working Paper 2007, zu den verschiedenen Missständen beim Rating strukturierter Wertpapiere. Die in den Credit Spreads von CDOs enthaltenen Risikoprämien sind detailliert von Bühler, Wolfgang/Trapp, Monika, Time-Varying Credit Risk and Liquidity Premia in Bond and CDS Markets, Working Paper, University of Mannheim, 2009, untersucht worden. Die Autoren stellen fest, dass immerhin ein Anteil von $35 \%$ der Spreads von Unternehmensanleihen (im Gegensatz zu nur $4 \%$ bei den Credit Default Swaps) bis zur Finanzkrise als Liquiditätsprämie interpretiert werden kann (bei andererseits $60 \%$ und $95 \%$ für das Kreditrisiko). Für die Zeit der Finanzkrise lassen sich dagegen keine stabilen Abschätzungen für die Kreditrisikoprämien und Liquiditätsrisikoprämien der Spreads ermitteln. Auch die Preisentwicklung der CDOs könnte durch Liquiditätsgesichtspunkte beeinflusst sein. In der Literatur ist allerdings darauf hingewiesen worden, dass die Praxis der Beratung der Emissionen durch die Ratingagenturen dazu missbraucht worden war, Pools qualitätsmäßig so zusammenzustellen, dass sie gerade noch den Ansprüchen der Ratingagenturen genügten. Mit diesem Verhalten wurde die Durchschnittsqualität der Pools an den Märkten längerfristig gesenkt. 
dem Verweis auf die Vorschriften der Bankenaufsicht belegen, in denen die von privaten Anbietern erteilten Ratings, die seit vielen Jahren erfolgreich allein als Marktsignale gedient hatten, nun auch für regulatorische $Z$ wecke zur Bemessung der Kapitalunterlegung von Kreditrisiken herangezogen wurden. Die Aufwertung und die möglicherweise zu Fehldispositionen Anlass gebenden Ermutigungen werden aber von Calomiris insbesondere für den amerikanischen Markt konstatiert: „Insurance companies, pension funds, mutual funds, and banks all face regulations that limit their ability to hold lowrated debts, and the Basel I and II capital requirements for banks place a great deal of weight on rating agency ratings. By granting enormous regulatory power to rating agencies, the government encouraged rating agencies to compete in relaxing the cost of regulation (through lax standards). Rating agencies that (in absence of regulatory reliance on ratings) saw their job as providing conservative and consistent opinions for investors changed their behaviour as the result of the regulatory use of ratings, and realised huge profits from the fees that they could earn from underestimating risk (and in the process provided institutional investors with plausible deniability)." ${ }^{72}$

Bezüglich der („toxischen“) Produkte, die bereits zu Beginn der Krise deutlich an Wert verloren haben, nämlich der Collateralized Debt Obligations in ihren verschiedenen Ausprägungen, wird neben einer größeren Transparenz ${ }^{73}$ und eines generellen Verbots mehrstufiger Verbriefungen wie MBS CDOs und

72 Calomiris, Charles W., The Subprime Turmoil: What's Old, What's New, and What's Next, http://voxeu.org, S. 1-6, eingesehen am 8. Oktober 2008, S. 3 trägt darüber hinaus noch ein paar wichtige Nebenapsekte vor: "Unbelievably, Congress and the Securities and Exchange Commission (SEC) were sending strong signals to the rating agencies in 2005 and 2006 to encourage greater ratings inflation in subprime-related collateralised debt obligations! In a little known subplot to the ratings-inflation story, the SEC proposed “anti-notching” regulations to implement Congress's mandate to avoid anti-competitive behaviour in the ratings industry. The proposed prohibitions of notching were directed primarily at the rating of CDOs and reflected lobbying pressure from ratings agencies that catered most to ratings shoppers. Notching arose when collateralised debt obligation sponsors brought a pool of securities to a rating agency to be rated that included debts not previously rated by that rating agency. For example, suppose that ratings shopping in the first generation of subprime securitisation had resulted in some mortgage-backed securities that were rated by Fitch but not Moody's (i. e., perhaps Fitch had been willing to bless a higher proportion of AAA debt relative to subprime mortgages than Moody's). When asked to rate the CDO that contained those debts issued by that subprime mortgage-backed securities conduit, Moody's would offer either to rate the underlying MBS from scratch, or to notch (adjust by a ratings downgrade) the ratings of those securities that had been given by Fitch.”

73 Dudley, aaO (Fn. 49), moniert die mangelnde Transparenz hinsichtlich der Bewertung, der Preisinformationen und der Risikokonzentration der strukturierten Wertpapiere. Es gibt keine Definition toxischer Wertpapiere. Unter toxischen strukturierten Produkten versteht man aber in der Regel Finanzinstrumente mit hohen Marktwertverlusten, mit hohen Bruttoverlusten oder mit hohen realisierten Verlusten in den Pools oder in einzelnen Tranchen. 
MBS CDOs2 ein verbindlicher Selbstbehalt (Equity Piece) der Emittenten bzw. Originatoren und Arrangeure gefordert, der eine Weitergabe der entsprechenden erwarteten Verluste an Dritte ausschließt. ${ }^{74}$ Damit sollen Adverse Selection- und Moral Hazard-Probleme vermindert werden, die aus der pauschalen Weitergabe aller Risiken resultieren können. Dieser rigorose Vorschlag kann aber ebenso wie der Vorschlag, von jeder emittierten Tranche der CDOs einen Selbstbehalt beim Verkäufer zu belassen, kontraproduktiv sein, weil damit der Risikotransfer insgesamt weitgehend unterbunden werden könnte, so dass auch die damit verbundenen Vorteile nicht mehr genutzt werden können. ${ }^{75}$ Die Umsetzung einer rigorosen Selbstbehaltsregel könnte nämlich dazu führen, dass der Markt austrocknet, was zu einem Effizienzverlust führen würde. Hier gilt es also nach Lösungen zu suchen, die die aufgetretenen Probleme des moralischen Risikos und der adversen Selektion vermeiden und dennoch die Transaktionen nicht mit prohibitiven Kosten belasten. $^{76}$

Ein weiteres Problem des Marktes für den Transfer von Kreditrisiken hatte sich daraus ergeben, dass die Risikoübernahme im Transferprozess stark auf einzelne Gesellschaften konzentriert war und ein Gegenparteirisiko entstand, das in der Krise insbesondere im Zuge der Insolvenz der AIG schlagend wurde. ${ }^{77}$ Aber auch der Verfall der sog. Monoliner machte das Gegenpartei-

74 Die EU-Kommission sieht vor, dass Anlagen der Kreditinstitute in strukturierte Papiere ab 2011 grundsätzlich nur noch dann möglich sein sollen, wenn der Originator einen materiellen Nettoanteil von mindestens fünf Prozent der verbrieften Positionen zurückbehält, wobei der Selbstbehalt in unterschiedlicher Weise, z. B. als Prozentanteil an allen Tranchen oder durch Rückbehalt der Erstverlustbranche erfüllt werden kann. Vgl. im Einzelnen Banh/Cluse, aaO (Fn. 48), S. 631.

75 Für den beispielsweise in Eichengreen, aaO (Fn. 57), erwähnten Vorschlag, einen Selbstbehalt bei allen emittierten Tranchen einzubehalten, spricht, dass sonst Anreize für Konstruktionen bestehen, bei denen hohe Verlustrisiken mit einer sehr geringen Wahrscheinlichkeit entstehen (Fat Tails).

76 Der Baseler Ausschuss plant eine Erhöhung der Risikogewichte für Wiederverbriefungen, eine Angleichung der Kapitalanforderungen für Verbriefungen im Handels- an die des Anlagebuchs und Anpassungen der Konversionsfaktoren für qualifizierte Liquiditätsfazilitäten. Darüber hinaus sollen Institute als Investoren in Zukunft Verbriefungsrisiken nur dann übernehmen dürfen, wenn eine Bestätigung des Originators vorliegt, dass dieser einen prozentualen Anteil des Risikos zurückbehält. Vgl. Deutsche Bundesbank, Das Baseler Regelwerk in der Praxis - Zur Umsetzung der fortgeschrittenen Baseler Ansätze in Deutschland, Monatsbericht, Jan. 2009, S. 59-79, S. 71.

77 Die AIG musste aufgrund von Zahlungen als Sicherungsgeber in der Subprime-Krise Milliardenverluste in ihrem Kreditversicherungsportfolio als Risikokäufer in Credit Default Swap Verträgen hinnehmen. Um eine Abstufung ihres Ratings zu verhindern, gewährte die Fed dem Konzern Mitte September 2008 nach dem Fall der Lehman Bank einen Kredit von $85 \mathrm{Mrd}$. US\$ und übernahm im Gegenzug einen Großteil der Aktien der Gesellschaft. Anfang Nov. 2008 war die Hilfe auf 150 Mrd. angewachsen, der vermutlich höchste Betrag einer Unterstützung für ein privates Unternehmen in der Geschichte der USA. 
risiko beim Transfer der Kreditrisiken deutlich. ${ }^{78}$ Zur Vermeidung der Gegenparteirisiken im Kreditversicherungsgeschäft sollte sich in der Zukunft für die Börsen ein attraktives Geschäftsfeld ergeben, weil diese über ihre Clearinghäuser erstens einen liquiden Markt für die Credit Default Swaps bilden und zweitens über ihre Marginsysteme sicherstellen können, dass die Sicherungsgeber auch in Krisensituationen ihren Verpflichtungen nachkommen können, so dass die Sicherungsnehmer kein explizites Gegenparteirisiko tragen müssen.

Ein weiterer Vorschlag im Hinblick auf den Abbau von Friktionen in der Wertschöpfungskette des Kreditrisikotransferprozesses betrifft das Verhalten vieler Anleger, die in der Vergangenheit offensichtlich sehr sorglos in die komplexen Produkte investiert haben und gezwungen werden könnten, die ökonomische Basis für ihre Anlageentscheidungen besser zu begründen und zu dokumentieren. Gorton misst im Übrigen der in 2006 gerade aufgekommenen Verfügbarkeit aggregierter Daten über die Preisentwicklung von Verbriefungstranchen, wie sie in der ABS.HE Indexfamilie zum Ausdruck kommt, insoweit eine Schlüsselrolle für die Dynamik der Subprime Krise zu, als die plötzliche Transparenz des Preisverfalls einzelner Anlagesegmente zugleich das Informationsdefizit darüber aufdeckte, in welchen Finanzinstrumenten und in welchen Portfolios sich dieser Wertverfall der ursprünglichen Hypothekenforderungen schließlich niederschlagen würde. „The introduction of these indices is important for two reasons. First, they provided a transparent price of subprime risk, albeit with subsequent liquidity problems. Second, it allowed for efficiently shorting of the subprime market. In addition to outright shorting, parties with long positions could hedge. The common knowledge problem concerning the value of subprime bonds may have been solved, but not the location problem. This is, of course, conjecture." ${ }^{\text {79 }}$ Das Beispiel zeigt, dass Transparenzanforderungen die gesamte Wertschöpfungskette bzw. die gesamte Produktvielfalt erfassen müssen und nicht auf einzelne Produkte, Prozesse oder Instrumente beschränkt werden dürfen. Transparenz muss auch hinsichtlich der Verteilung der Risiken auf die verschiedenen Marktteilnehmer sowie über die Konzentration dieser Risiken bei

78 Die als Monoliner bezeichneten Anleiheversicherer übernehmen von institutionellen Anlegern das Ausfallrisiko der in ihrem Portfolio gehaltenen Anleihen und erhalten dafür eine Risikoprämie. Basis dieser Versicherungsleistung ist ihr eigenes hohes Rating, da viele institutionelle Anleger nur in Anleihen höchster Bonität investieren dürfen oder in andere Anleihen, sofern diese durch eine Versicherung mit höchster Bonität abgesichert sind. Werden Monoliner von Ratingagenturen herabgestuft, müssen in den Portfolios der Institutionellen entsprechende Anpassungen vorgenommen werden.

79 Gorton, aaO (Fn. 4), S. 32-33. Gorton entwickelt spezifische Hypothesen zur Bedeutung des Zusammenspiels von verfügbaren und nicht verfügbaren Informationen über die von der Preisentwicklung an den Wohnimmobilienmärkten abhängigen Asset Backed Securities. 
bestimmten Marktteilnehmern bestehen, eine Forderung, die das White Paper von Issing et al. zum Vorschlag der „Risk Map“ ausgearbeitet hat.

Neben den verschiedenen Vorschlägen zum Abbau von Friktionen in der stark aufgegliederten Wertschöpfungskette des Kreditprozesses konzentrieren sich die Vorschläge, die auf die Verantwortung der Institute selbst abstellen, auf Verbesserungen im Aufbau und im Prozess des Risikomanagements der Banken.

\section{Verbesserungen in der Risikokontrolle und im Risikomanagement}

Es ist schon im Zusammenhang mit den bankaufsichtlichen Vorschriften darauf hingewiesen worden, dass sich das Instrumentarium der Risikomessung und Risikosteuerung sehr technisiert hat. Dabei ist das Augenmerk auf Systeme gelegt worden, die auf Informationen aus verfügbaren Datenreihen der Vergangenheit aufbauen. Die Finanzkrise hat nun gezeigt, dass die gemessenen Kursvolatilitäten und Kurskorrelationen vieler Assets mit dem Aufkommen der Krise starken Veränderungen unterworfen wurden. Dabei war es auch weniger bedeutend, ob die zuvor verwendeten Datenreihen eine kürzere oder längere Historie korrekt abgebildet haben. Die Volatilitäten und Korrelationen in Krisensituationen zeigten andere Merkmale und Muster als die über Jahre für Assetpreise und Renditen gemessenen Risiken. Da es noch keine Erfahrungen mit der jetzigen Liquiditäts- und Solvenzkrise gegeben haben konnte, waren auch die in den Stressszenarien letztlich entscheidenden Risikofaktoren nicht in ausreichendem Maße berücksichtigen worden.

Als Forderung zur Einführung robuster Checks kann auch der Hinweis gedeutet werden, dass sich Frühwarnindikatoren für Risiken außerhalb der eigentlichen Risikomesssysteme aufbauen lassen, wenn z.B. hohe Spreads am Markt beobachtet werden können, die dafür sprechen, dass in den entsprechenden Positionen Risikoprämien enthalten sind. Andererseits hat sich in der Subprime Krise gezeigt, dass Spreads bis zum Eintritt der Krise zum Teil völlig insensitiv bezüglich der eingegangenen Risiken waren. Als Lösungsvorschläge werden hier insbesondere die Verbesserung der Stresstests und der Szenarioanalysen vorgebracht, der Ausbau und die Stärkung von Plausibilitätstests und, woran der Basler Ausschuss für Bankenaufsicht und die Bankaufsichtsbehörden in besonderer Weise gearbeitet haben, der Ausbau des Liquiditätsrisikomanagements. Es könnte auch überlegt werden, die aktuellen Verfahren der Risikomessung um eine Variante zu erweitern, bei der die Risikomessung durch einen Abstand zu einem fundamentalen Wert erfolgt, der von der Bankenaufsicht oder der Bundesbank vorgegeben wird. So könnte in der Boomphase die durch die Zuschreibungen der Asset Values ermöglichte Vergrößerung des regulativen Eigenkapitals abgemildert bzw. korrigiert werden. Unabhängig von den konkreten Fortschritten in der Erfassung und 
Quantifizierung von Risiken ist aber auch die Einführung von Maßnahmen erforderlich, die sicherstellen, dass die im Risikocontrolling gewonnenen Erkenntnisse auch in die Risikopolitik der Institute umgesetzt werden.

Hinsichtlich der Risikomessung mit Hilfe des Value-at-Risk Ansatzes ${ }^{80}$ liegt der Verdacht nahe, dass die Banken in der Vergangenheit sehr hohe mögliche Verluste unterbewertet haben, sofern deren Eintrittswahrscheinlichkeit als äußerst klein eingestuft wurde. Ein Value-at-Risk von Null kann einen sehr hohen Verlustbetrag beinhalten, auch wenn das gemessene Risiko unter der Messschwelle liegt, weil das Verlustereignis eine für die Vorgabe zu niedrige Eintrittswahrscheinlichkeit aufweist. „When we consider the risk of extreme outcomes, a number of further factors come into play. One is 'disaster myopia", the tendency to not want to think about highly improbable but likely extremely costly events (like airplane crashes). The second is our very limited human capacity to predict outcomes of processes in which all the variables are highly endogenous." ${ }^{\prime 1}$ Die in der Krise zu Tage getretenen Verluste haben deutlich gemacht, dass die Häufigkeit hoher Verluste größer ist als in den Systemen unterstellt.

\section{Ausblick}

An die Banken richten sich viele unterschiedliche Erwartungen, einmal Finanzstabilität, ein andermal Arbeitsplätze, dann Mittelstandsfinanzierung oder die Rettung von Konzernen vor der Insolvenz. Die Konflikte, die aus öffentlichen Ansprüchen an private Unternehmen entstehen, werden übersehen. ${ }^{82}$ Gerade weil die Kreditwirtschaft gegenüber anderen Akteuren an den Märkten unverzichtbare Leistungen erbringt, sind die Ansprüche und Erwartungen besonders ausgeprägt. Letztlich sind diese für die Gesamtwirtschaft unverzichtbaren Funktionen auch der Grund, dass der Finanzsektor in besonderer Weise ausgeprägten Regulierungen unterliegt.

Im Rahmen des vorgegebenen Regulierungsrahmens müssen sich aber Kreditinstitute nach rein marktwirtschaftlichen Kriterien betätigen dürfen und daher ihre Steuerungssysteme und Entscheidungen auf ihren eigenen bzw. den Vorteil ihrer Eigentümer (Shareholder Value) ausrichten. Kontraproduktiv wäre es dagegen, sie jenseits der bankaufsichtlichen Regulierungen mit ge-

$80 \mathrm{Zu}$ alternativen Verfahren der Risikomessung bei seltenen Ereignissen vgl. MrTTNIK, Stefan/Yener, Tina, Value-at-Risk and Expected Shortfall for Rare Events, CFS Working Paper 2008/14.

81 Issing ET AL., aaO (Fn. 38), S. 26. Die Autoren weisen auch darauf hin, dass offenbar viele neuartige Zahlungscharakteristiken im Kreditrisikotransfer mit der expliziten Zielsetzung konstruiert worden waren, Risiken in die Ränder der Verlustverteilungen zu verschieben, so dass die Verlustwahrscheinlichkeit vermindert, die Verlusthöhe (im unwahrscheinlichen Fall eines Verlustes) aber stark erhöht wurde.

82 Vgl. Hellwig, Wenn die Interessen verwischen, FAZ v. 22. November 2008. 
samtwirtschaftlichen Aufgaben und Ansprüchen zu konfrontieren. Ein weitergehender Staatseinfluss ist daher auf längere Sicht nach einer hier nicht zu diskutierenden Übergangszeit genauso abzulehnen wie eine Gleichbehandlung aller Akteure an den Finanzmärkten. Dies würde einerseits den Fortschrift im Bereich der Finanzwirtschaft behindern und andererseits Anlass zu einem noch weitergehenden gleichgerichteten Verhalten geben, worin der Keim einer neuen internationalen Finanzkrise schon enthalten sein könnte.

In einem Interview mit dem Präsidenten der Weltbank Robert Zoellick weist dieser auf eine weitere Gefahr hin, die es zu vermeiden gilt: „Ich plädiere sehr dafür, die richtigen Lehren aus Krisen für die Zukunft zu ziehen. Leider geschieht das nicht immer und überall. Sehen Sie sich zum Beispiel die riesigen Mengen von Liquidität an, die Notenbanken rund um die Welt derzeit auf die Märkte pumpen. Ganz ähnlich hat die Federal Reserve nach dem Zerplatzen der Internetblase vor einigen Jahren reagiert. Meine Sorge ist, dass wir ein noch viel größeres Problem schaffen, wenn das Geld nicht rechtzeitig dem System wieder entzogen wird. Ich bin übrigens nicht dafür, die Verbriefung von Forderungen künftig zu verbieten. Aber wir sollten sicherstellen, dass derjenige, der einen Kredit vergibt, auch einen Teil des Ausfallrisikos behält. ${ }^{“{ }^{-} 3}$

Die hier angestellten Überlegungen beziehen sich nicht auf den aktuellen Fragen der Bewältigung der Finanzkrise und der Diskussion um die Ausgestaltung der Bad Banks, sondern mit den eher prinzipiellen Fragen der Veränderungen im Risikocontrolling der Kreditinstitute und in der Bankenaufsicht. Diese werden aber in der Tat erst dann relevant, wenn erstens die aktuelle Krisensituation mehr oder weniger bewältigt ist und wenn zweitens bei der Bewältigung der Krise nicht Fehler gemacht werden, die den Keim für eine neue Krise schon in sich tragen. Mit anderen Worten richten sich die vorgetragenen Überlegungen auf die generelle Formulierung von Grundsätzen für eine sicherheitsorientierte und nachhaltige Risikopolitik der Banken und der Bankenaufsicht. 20. November 2008. 